IZA DP No. 5819

Destined for (Un)Happiness:

Does Childhood Predict Adult Life Satisfaction?

Paul Frijters

David W. Johnston

Michael A. Shields

June 2011 


\title{
Destined for (Un)Happiness: Does Childhood Predict Adult Life Satisfaction?
}

\author{
Paul Frijters \\ University of Queensland \\ and IZA \\ David W. Johnston \\ CHE, Monash University \\ Michael A. Shields \\ CHE, Monash University, \\ University of Melbourne and IZA
}

Discussion Paper No. 5819

June 2011

IZA

P.O. Box 7240

53072 Bonn

Germany

Phone: $+49-228-3894-0$

Fax: +49-228-3894-180

E-mail: iza@iza.org

Any opinions expressed here are those of the author(s) and not those of IZA. Research published in this series may include views on policy, but the institute itself takes no institutional policy positions.

The Institute for the Study of Labor (IZA) in Bonn is a local and virtual international research center and a place of communication between science, politics and business. IZA is an independent nonprofit organization supported by Deutsche Post Foundation. The center is associated with the University of Bonn and offers a stimulating research environment through its international network, workshops and conferences, data service, project support, research visits and doctoral program. IZA engages in (i) original and internationally competitive research in all fields of labor economics, (ii) development of policy concepts, and (iii) dissemination of research results and concepts to the interested public.

IZA Discussion Papers often represent preliminary work and are circulated to encourage discussion. Citation of such a paper should account for its provisional character. A revised version may be available directly from the author. 


\section{ABSTRACT \\ Destined for (Un)Happiness: Does Childhood Predict Adult Life Satisfaction?*}

In this paper we address the question of how much of adult life satisfaction is predicted by childhood traits, parental characteristics and family socioeconomic status. Given the current focus of many national governments on measuring population well-being, and renewed focus on effective policy interventions to aid disadvantaged children, we study a cohort of children born in a particular week in 1958 in Britain who have been repeatedly surveyed for 50 years. Importantly, at four points in their adult lives this cohort has been asked about their life satisfaction (at ages 33,42, 46, and 50). A substantive finding is that characteristics of the child and family at birth predict no more than $1.2 \%$ of the variance in average adult life satisfaction. A comprehensive set of child and family characteristics at ages 7, 11 and 16 increases the predictive power to only $2.8 \%, 4.3 \%$ and $6.8 \%$, respectively. We find that the conventional measures of family socioeconomic status, in the form of parental education, occupational class and family income, are not strong predictors of adult life satisfaction. However, we find robust evidence that non-cognitive skills as measured by childhood behavioural-emotional problems, and social maladjustment, are powerful predictors of whether a child grows up to be a satisfied adult. We also find that some aspects of personality are important predictors. Adding contemporaneous adulthood variables for health and socio-economic status increases the predictability of average life satisfaction to $15.6 \%$, while adding long-lags of life satisfaction increases the predictive power to a maximum of 35.5\%. Repeating our analyses using data from the 1970 British Cohort Study confirms our main findings. Overall, the results presented in the paper point to average adult life satisfaction not being strongly predictable from a wide-range of childhood and family characteristics by age 16, which implies that there is high equality of opportunity to live a satisfied life, at least for individuals born in Britain in 1958 and 1970.

JEL Classification: I1, J1

Keywords: childhood, socioeconomic status, life satisfaction, non-cognitive, cognitive

Corresponding author:

Michael A. Shields

Department of Economics

University of Melbourne

Australia 3010

E-mail: mshields@unimelb.edu.au

\footnotetext{
* We would like to thank the Data Archive at Essex University for providing access to the data used in this paper. We are also grateful to Bruce Hollingsworth, Andrew Oswald, Nick Powdthavee and Carol Propper for valuable comments, and seminar participants at the Universities of Monash, Bristol, Melbourne, Wellington and York.
} 


\section{Introduction}

There is a substantial multi-disciplinary literature that investigates the links between childhood and parental characteristics, family circumstances, and a wide-range of later life outcomes, including educational attainment, health, employment, income, crime, behaviour and lifestyle (see, for example, Ahlburg, 1998; Currie and Thomas, 1995, 1999; McLeod and Kaiser, 2004; Case et al., 2005; Black et al., 2005; Blanden et al., 2007; Mensah and Hobcraft, 2008; Currie, 2009; Smith, 2009; Conti and Heckman, 2010; Contoyannis and Dooley, 2010; Currie et al., 2010; Frijters et al., 2010; Currie, 2011; Goodman et al., 2011; Holmlund et al., 2011; and Salm and Schunk, 2011). This literature clearly shows that early life characteristics and circumstances have some power in predicting adult outcomes. Gaining insights into these links, and in particular being able to identify causal mechanisms and pathways, is key to better understanding the intergenerational transmission of socioeconomic status and the extent of social mobility. Recent years have seen the economics literature expand to distinguish between cognitive and non-cognitive (or social) skills, as well as focus on personality traits, in determining life outcomes (see, for example, Heckman et al., 2006; Carneiro et al., 2007; Borghans et al., 2008; Almlund et al., 2011). As stated by Heckman et al. (2006), "Common sense suggests that personality traits, persistence, motivation, and charm matter for success in life” (p.412). It is also argued that 'skills beget skills', that the largest return to investing in children is when they are young (pre-school), and that non-cognitive skills are likely to be more malleable than cognitive skills. The success of the Perry Preschool Program in the US in the early 1960's is widely cited as strong evidence for the economic case of early public investment in disadvantaged children (see, for example, Heckman et al., 2010). There is also a strong emphasis in the literature on the importance of families as investors in children and producers of skills (see, for example, Cunha and Heckman, 2008; Cunha et al., 2010; Heckman, 2011).

At the same time as this rapid increase in the literature on the importance of childhood, there has been a dramatic growth in the attention paid by the economics profession in better understanding the factors determining an individual's wellbeing, happiness or life satisfaction (for example, see the reviews by Frey and Stutzer, 2002; Layard, 2005; Di Tella and MacCulloch, 2006; Clark et al., 2008a; and Dolan et al., 2008). One salient result from this literature is that typical regression models of life satisfaction, capturing a wide-range of socioeconomic and demographic characteristics of adults, typically fails to account for more than about $10-15 \%$ of the observed variation in life satisfaction or happiness. This literature, however, has tended to focus on relating adult economic circumstances (particularly unemployment and income) to life satisfaction with individual panel data, particularly the 
British Household Panel Survey (BHPS) and the German Socioeconomic Panel (GSOEP). These panel surveys contain little information about the childhood characteristics and early family circumstances of the adult sample members. Following insights from psychology, however, there is a clear acknowledgment that the past is important (including a genetic component), which has placed an emphasis on using individual fixed-effects models as a method to control for background and individuals traits such as personality (Ferrer-i-Carbonel and Frijters, 2004). In this respect, De Neve et al. (2010) compared a sample of twins drawn from the US National Longitudinal Study of Adolescent Health, and estimated that one-third of the variance in individual life satisfaction can be attributed to genetic differences. The widely cited twins study by Lykken and Tellegen (1996) found the genetic component of wellbeing to be around 50\%, and that the "heritability of the stable component of subjective well-being approaches 80\%”. Lykken and Tellegen go as far as to conclude that, "It may be that trying to be happier is as futile as trying to be taller and therefore is counterproductive” (p.189).

In this paper we attempt to bring these two literatures together, by shedding light on the childhood traits, characteristics and family circumstances that predict average adult life satisfaction. We do this using data from a cohort of children born in the UK in 1958 who have been tracked for 50 years - the National Child Development Study (NCDS). We also replicate our analyses using data from the 1970 British Cohort Study (BC70). While both of these cohort studies have been used extensively to look at child development and adult outcomes, we are unaware of any research that focuses on the overall predictability of adult life satisfaction over nearly a twenty year period and therefore answers the question of whether or not some children are destined to live unsatisfied lives. ${ }^{1}$

We ask the following type of question - suppose you knew a child who, by the age of 16, had the worst possible start in life. She lived in a poor neighbourhood, was shy and introverted, her father had been absent from the time she was born, her mother was unemployed and had mental health issues, and there was little income or financial security in the household. In addition, the child was relatively unhealthy for her age, she often displayed anti social behaviour, and her cognitive development was poor. Could we confidently predict that this girl would become an unhappy adult? Now compare this child's situation to a girl of the same age that lived only 5 miles away, but in a wealthy neighbourhood with a great school. Her mother and father were highly educated and both employed in professional

\footnotetext{
${ }^{1}$ Mensah and Hobcraft (2008) use data from the NCDS and BC70, relating childhood characteristics observed up to the age of 16 to a number of health outcomes at age 30 and 33, including an indicator of mental health. They find an important predictive role for early cognitive and behavioural development in predicting health outcomes. However, they do not document or discuss the overall predictability of these outcomes from childhood characteristics.
} 
jobs. Money was never an issue in her household, and she was healthy, and had high cognitive ability. Was this girl, with the 'good' start in life, destined to be a satisfied or happy adult?

In the UK context this type of question directly relates to the recent high profile report chaired by Frank Field that reviewed the evidence on the issue of preventing poor children becoming poor adults (Field, 2010). The review concluded that there is 'overwhelming evidence that children's life chances are most heavily predicted on their development in the first five years of life' (p. 5). Furthermore, it is argued that for many disadvantaged children life's race is effectively over at an early age: 'schools are not effective at closing that gap; children who arrive in the bottom range of ability tend to stay there' (p.7). However, the review also notes that increased income, on its own, would be insufficient to improve the life chances of poor children (p.82). More generally, many early life factors were highlighted as important factors in explaining good adult outcomes, including family background, parental education, the quality of parenting, good maternal mental health, and good opportunities for learning and development.

The questions we address in this paper are also topical because they closely relate to the recent focus by the UK Government on measuring national wellbeing, and designing policies directly aimed at improving wellbeing. ${ }^{2}$ A recent quote by UK Prime Minister David Cameron confirms this position: "It's time we admitted that there's more to life than money and it's time we focused not just on GDP but on GWB - general wellbeing" 3 . It is therefore important to know the extent to which there is equal opportunity for happiness in the UK.

In this paper we therefore provide timely research by establishing the long-term relationship between childhood characteristics and adult life satisfaction using data from the National Child Development Study (NCDS). The NCDS has been well used for socioeconomic research because it has followed the children born in Britain in a particular week in 1958 for half a century. At ages 0, 7, 11 and 16, the children and the people around them (parents, teachers) were given extensive questionnaires and tests to ascertain their health, cognitive ability, behaviour, personality, and family life. These children were then also interviewed as adults when they were aged 33, 42, 46, and 50, to see how they fared, including a measure of their life satisfaction. We also test the robustness of the main results by using data from the 1970 British Cohort Study (BC70). We believe that the predictability of adult life satisfaction by childhood and adolescent characteristics is an important policy issue and of interest to many disciplines including economics, psychology and philosophy. The extent to which

\footnotetext{
2 The Office for National Statistics (ONS) is currently (to be completed in 2011) undertaking a consultative exercise focused on how best to measure population wellbeing. Also see the report by Dolan et al. (2011).

${ }^{3}$ Quoted in the Guardian newspaper on the $14^{\text {th }}$ November 2010.
} 
individuals from differing socioeconomic backgrounds have the opportunity to be satisfied adults is also of clear interest to policy-makers.

\section{Methodology and Results}

\subsection{General methodology}

At the most general level, we can think of the level of life satisfaction $L S$ of individual $i$ at time $t$ as being a function of current and past variables:

$$
L S_{i t}=f\left(p_{i t}, x_{i t} ; p_{i t-1}, x_{i t-1} ; . ; p_{i 0}, x_{i 0}\right)
$$

Here, $p_{i t}$ denotes all the trait characteristics of an individual and $x_{i t}$ denotes all the socio-economic factors, incidental factors, the perceived outcomes of other individuals, and all the residual circumstances in a person's life. The role of the past realisations of these variables in life satisfaction is in terms of shaping a reference position: $\left\{p_{i t-1}, x_{i t-1}\right\}$ denotes the variables in the previous period and it is envisaged that they are important to an individual as a frame of comparison.

Typically, we neither observe $p_{i t}, x_{i t}$, or all the previous realisations of these variables. At best, we can observe proxies $\left\{P_{i t}, X_{i t}\right\}$ of these variables. Also, the general functional form $f($.$) is unknown a$ priori and we typically accept linear approximations. Therefore, a more common 'workhorse' approximation to (1) is an estimable equation of the form:

$$
L S_{i t}=P_{i t} \alpha+X_{i t} \beta+P_{i t^{-}} \gamma_{0}+X_{i t^{-}} \gamma_{1}+e_{i t}
$$

Where $P_{i t^{-}}$denotes the available historical information on $P_{i t}$ and $e_{i t}$ denotes the error term. This equation can be seen as the first-order linear approximation to $f($.$) with the missing variables,$ measurement errors, and non-linearities going into the error term. In this paper we attempt to estimate (2) in specifications that combine the detailed childhood and adolescent information available in the NCDS (and BC70) with information on the contemporary circumstances adults find themselves in. In addition to estimating equation (2), we add $L S_{i t-1}, L S_{i t-2}, .$. as approximations for missing variables in the term $\left(P_{i t}{ }^{-} \gamma_{0}+X_{i t}{ }^{-} \gamma_{1}\right)$, which significantly improves the model fit. 
Equation (2) also allows for an interpretation of even simpler estimation equations that only involve variables measured in childhood by interpreting the contemporaneous variables $\left\{P_{i t}, X_{i t}\right\}$ themselves as the outcome of early-life circumstances and intermediary factors. If we presume:

$$
\begin{aligned}
& P_{i t}=g_{p t}\left(P_{i 0}, X_{i 0}\right)+u_{p i t} \\
& X_{i t}=g_{x t}\left(P_{i 0}, X_{i 0}\right)+u_{x i t}
\end{aligned}
$$

Which says that current variables are generated via an unknown process $\left(g_{t}().\right)$ from early-life variables $\left\{P_{i 0}, X_{i 0}\right\}$ and combined with other factors $u_{i t}$, then we can re-write equation 2 as:

$$
L S_{i t}=\sum_{t}\left[g_{p t}\left(P_{i 0}, X_{i 0}\right) \alpha_{t}+g_{x t}\left(P_{i 0}, X_{i 0}\right) \beta_{t}\right]+v_{i t}
$$

Where $v_{i t}$ is a consolidated error term. If we now take a linear approximation to (4) we can write:

$$
L S_{i t}=P_{i 0} \alpha+X_{i 0} \beta+\tilde{v}_{i t}
$$

which only includes childhood circumstances and is an equation that we directly estimate. This train of thought shows that we can interpret the effects of childhood variables on current life satisfaction as the reduced form effects they have via current unmeasured variables and unmeasured comparison levels. One generically expects variables in early childhood to affect later life outcomes via their influence on more contemporaneous variables, leading to the question what the form and strength of the functions $g_{t}($.$) are, where u_{i t}$ is one measure of the strength of $g_{t}($.$) . Intuitively, the stronger is g_{t}($.$) and the$ smaller $u_{i t}$, then later life outcomes are tied to early-life outcomes and the less is the role for the intermediary variables (luck and unforeseen interactions). A direct statistic of the strength of $g_{t}($.) is the degree to which any current variable in $\left\{P_{i t}, X_{i t}\right\}$ can be predicted by early-life circumstances. Therefore we will directly estimate (5) when we look at the degree to which childhood variables can predict life satisfaction, and we will also estimate equation (2). 


\subsection{Identifying the fixed-component of adult life satisfaction}

One of the key theories in the wellbeing literature is that of 'set-point', where individuals are assumed to have a set point (or baseline) for their life satisfaction, which they return to following perturbations or shocks (see, for example, Headey and Wearing, 1992; Myers and Diener, 1995; Lykken, 1999; and Fujita and Diener, 2005). In terms of the general model above, this would mean that the important psychological variables are fixed $\left(P_{i t}=P_{i t-1}=. .=P_{i 0}\right)$ and that the long-run effect of socio-economic

variables is zero $\left(\sum_{s} \gamma_{s}=0\right)$. This is hence a dual theory of non-vanishing effects of early life psychological variables and full adaptation to socio-economic shocks. Examples of studies that provide evidence on the extent to which individuals adapt to major life events are Lucas et al. (2003, 2004), Clark et al. (2008b) and Frijters et al. (2011). Weiss et al. (2008) suggest that, "Subjective wellbeing is linked to personality by common genes and that personality may form an "affective reserve" relevant to set-point maintenance and changes in set point over time".

In order to obtain an estimate of the component of life satisfaction that is fixed, and therefore to shed additional light on the validity of the set-point theory, we can model individual-level life satisfaction at time $t$ of adults $i$ as being associated with their circumstances in childhoods:

$$
\begin{aligned}
& L S_{i t}^{a}=X_{i}^{c} \beta^{c}+v_{i}+u_{i t} \\
& L S_{i}^{a}=X_{i}^{c} \beta^{c}+v_{i}+\overline{u_{i t}}
\end{aligned}
$$

where $L S_{i t}^{c}$ is the life satisfaction of an adult individual $i$ at age $t ; X_{i}^{c}$ is a vector of observable childhood characteristics of that adult (including psychological traits); $v_{i}$ is an individual-specific trait orthogonal to observed childhood variables; and $u_{i t}$ is a random error term that captures all transient factors orthogonal to the fixed characteristics.

The second line in equation (6) shows how we can interpret adult life satisfaction, which is the average of the life satisfactions observed over the four survey points (ages 33 to 50). The importance of fixed observed and unobserved terms remains unaffected by the aggregation, but the residual error term is now an average of the random error terms so that the importance of any momentary factors will decrease. The difference between the variation in life satisfaction at a particular age and the aggregate life satisfaction is informative as to how large the importance of fixed traits is for the total amount of variation: 


$$
\begin{aligned}
& \operatorname{Var}\left(L S_{i t}^{a}\right)=\operatorname{Var}\left(X_{i}^{c} \beta^{c}+v_{i}\right)+\operatorname{Var}\left(u_{i t}\right) \\
& \operatorname{Var}\left(\overline{L S_{i}^{a}}\right)=\operatorname{Var}\left(X_{i}^{c} \beta^{c}+v_{i}\right)+\frac{\sum_{t} \operatorname{Var}\left(u_{i t}\right)}{n^{2}}
\end{aligned}
$$

Where $n$ denotes the number of periods aggregated over and the two elements in this decomposition refer to fixed traits and transient traits, therefore allowing for the possibility that the variance of the transient traits varies over time.

The fixed traits (or component) in this context means that it is no longer changing after the first measure of life satisfaction. While we are able to calculate the importance of this fixed component, we will not be able to identify exactly when the component was formed, as it could be genetic, formed in infancy, in childhood, as an adolescent, or even in early adult life. All we can say for certain is that these traits no longer change after the first life satisfaction observation, although within the logic of setpoint theory we would normally think of traits that change little after childhood (such as cognitive ability).

\section{Data and Sample Characteristics}

\subsection{The National Child Development Study (NCDS)}

The NCDS covers a cohort of around 17,400 children born in England, Scotland and Wales, in one particular week in March 1958, with follow-on data having been collected in 1965 (at age 7), 1969 (age 11), 1974 (age 16), 1981 (age 23), 1991 (age 33), 1999-2000 (age 41-42), 2004 (age 46) and 2008-09 (age 50-51). Since the 1981 sweep of the data, the cohort member has been the main respondent, whereas earlier data was collected mostly from parents but also from teachers and health workers. For the majority of the birth cohort, therefore, detailed information about their lives over 50 years is available to researchers. The NCDS has been widely used to study child development and adult outcomes across many disciplines, although there are few studies that have yet included data from the recently released 2008/09 survey. Like all longitudinal studies the NCDS suffers from attrition and missing information, which might impact on the extent to which the results can be generalised to the 
wider cohort. However, it has been found that attrition in the NCDS is not systematically associated with socioeconomic status (Case et al., 2005). ${ }^{4}$

In this paper we use data from cohort members for who we observe information at birth, age 7, age 11 and age16, and also observe at least one value of their adult life satisfaction up to 2008/9 (age 50). To be precise, starting with 17,415 observations in 1958, we lose 2,920 due to missing information at age 7, 2,068 due to missing information at age 11, and 2,823 due to missing information at age 16. These sample restrictions leave us 9,604 observations with non-missing information from birth, age 7, age 11 and age 16. However, we lose a further 1,627 observations that do not have any adult life satisfaction information. Therefore, our main estimation sample contains 7,977 children, or $46 \%$ of the original birth cohort. ${ }^{5}$

\subsection{Childhood and family characteristics used to predict adult life satisfaction}

Out of the extensive information (hundreds of variables) contained in the childhood and adolescent waves of the NCDS (i.e. birth, age 7, age 11 and age 16), provided mostly by parents and teachers, the challenge is to select the variables that are likely to be key drivers of 'success' in life. To do this and focus our variable selection, we turn to the factors identified in the literature highlighted in the introduction, and therefore we particularly focus on socioeconomic status, health, cognitive ability, non-cognitive attributes and personality. Our modelling approach is going to be sequential. We start with just birth information predicting average adult life satisfaction, then we add in information observed at age 7,11 and 16, sequentially. The list of variables we use is provided with their means and standard deviations in Table 1.Fuller descriptions of key variables are provided in the Appendix. Note that all of the continuous test scores and indices have been coded 0 -1, to ease interpretation of the model results later in the paper.

From the birth data we focus on whether or not the mother of the child smoked during pregnancy, birth weight and gestation weeks, whether the birth was induced, whether or not the method of delivery was a caesarean, whether there was any abnormality during pregnancy, number of older

\footnotetext{
${ }^{4}$ In our context, if we run a probit attrition model, where the dependent variable is equal to 1 if the individual remains in the survey at age 50, and 0 otherwise, we do find that some of the child and family characteristics that we find to be significant predictors of average adult life satisfaction are also significant predictors of sample attrition. In particular we find some evidence that children with early behavioural problems, and those with social maladjustment, are less likely to be observed in the data at age 50, while those with higher cognitive ability are more likely to remain in the data.

${ }^{5}$ We could have selected our working sample in two other ways. We could have increased the sample by around 2,000 if in our later empirical models we retained children who were missing in one or two of the children surveys, and included missing controls for them in the models. Alternatively, we could have reduced the sample if we selected only adults for whom we observe all four observations on life satisfaction. Most importantly, using these alternative sample selections we have found that the main results of this paper regarding the most powerful childhood predictors, and the overall power of childhood characteristics, to predict average adult life satisfaction are substantively unchanged.
} 
siblings, mother's and father's age, whether the mother was single, whether the mother or father had more than the minimum years of schooling and father's occupational class. Note that the first time that family income is measured in the NCDS is in 1974 (age 16).

The age 7 (1965) predictors we use are number of siblings, the number of chronic health conditions the child has, an indicator for whether the child has a physical handicap or disabling condition, whether the mother worked before the child was of school age, wether the biological father is in the household, father's occupational class and variables indicating major family difficulties. The latter variables capture difficulties with housing, finances, physical illness, mental illness, death of father or mother, domestic tension, unemployment and alcoholism. Importantly, this information about the difficulties faced by the family is provided/assessed independently by a health worker following a lengthy interview with the main responding parent, so is likely to be more an objective measure of family problems than if self-reported by parents. To capture early life cognitive skills we include a teacher's assessment of the child's ability and scores from arithmetic, copy design, draw-a-man and group reading tests. Following studies such as Carneiro et al. (2007) and Cunha and Heckman (2008), we test if childhood non-cognitive attributes (or skills) are important predictors of future life satisfaction by including information in our models about childhood behavioural-emotional problems, and information about social skills captured by the British Social Adjustment Guide total score. By including these variables we are able to establish the relative power of cognitive versus non-cognitive skills in predicting a satisfied life.

The predictors at age 11 (1969) we focus on are number of siblings, height and weight of the child, an indicator for any physical handicap or disability, father's occupational class, an indicator for whether the biological father is in the household and an extensive range of measures of cognitive and non-cognitive skills similar to those collected at age 7. These include the scores from a general ability test, a mathematics test, as well as an evaluation made by teachers of whether the child was 'outstanding'.

A positive feature of the 1974 (age 16) data collection, given the recent focus by economists on the development and role of personality (see, for example, Borghans et al., 2008; Almlund et al., 2011), is that teachers are asked about the extent to which each child is impulsive, even-tempered, aggressive, rigid, withdrawn and hard working. We also know whether the child has been in trouble with the police, and have updated information about number of siblings, father's occupational class, cognitive skills and non-cognitive skills. In addition, for the first time household income is measured in the survey. 
Overall, these four sets of information about childhood and adolescence capture most of the factors that are readily measurable and have been found in the multidisciplinary literature to determine life chances. At the least, these variables account for the main characteristics of children, or the circumstances in which they were raised, that are used by professionals such as teachers, doctors and social workers, to identify the most disadvantaged children in society.

\subsection{Adult life satisfaction}

At ages 33, 42, 46 and 50 the cohort members were asked the following question: "Here is a scale from 0 to 10 , where ' 0 ' means that you are completely dissatisfied and '10' means that you are completely satisfied. Please enter the number which corresponds with how satisfied or dissatisfied you are with the way life has turned out so far." This is essentially the same question used in many surveys that have formed the basis of the large life satisfaction literature (see Clark et al., 2008a), and the NCDS data on life satisfaction (at age 33) has been used, for example, by Blanchflower and Oswald (1998) in their study of entrepreneurship, but they did not include childhood variables in their model. The mean values of life satisfaction in the NCDS for each age are provided at the top of Table 1, and distributions are provided in Figure 1. The average value across all ages (our main dependant variable) is 7.36, the mode response is 8 for all ages, and the distribution is left-skewed as is typically found. The majority of this UK sample report their satisfaction to be at least 7 on the $11(0-10)$ point scale, which is similar to that found using data from the British Household Panel Study (BHPS). The distribution looks the same at all ages, with the exception of the age 46 responses, where there is a slightly lower proportion of the sample reporting their life satisfaction to be below 6 .

\subsection{Sample characteristics}

Table 1 provides the characteristics of the sample at birth, ages 7, 11 and 16, as well as for key socioeconomics variables at age 50. In 1958 the average age of the mother at birth was 27.6 years and the father was aged 30.7 years, and about only one-quarter of parents had stayed on at school after the minimum leaving age. At that time the majority of fathers (52\%) worked in manual skilled jobs, while about $18 \%$ worked in either professional (4.4\%) or semi-professional (13.6\%) jobs. About one-third (33\%) of mothers smoked when pregnant, 6\% of the children were born with low birth-weight, 3\% were born by caesarean, labour was induced for $13 \%$ of the cohort and, on average, they had 1.2 older siblings when born. By age 7 the average number of chronic health conditions was 0.5, but only 3.7\% of these young children were reported to have a physical handicap or disability. In the age 7 survey, 
$27 \%$ of mothers reported to have worked before the child was of school age, the biological father was absent from the household for 5.8\% of children, and the proportion of fathers (in the household) working in unskilled jobs has fallen from the $8.7 \%$ observed at birth to $5.9 \%$ some seven years later. Health workers assessed that 5.4\% of families had difficulties with housing, 5.9\% experienced financial problems, 4.1\% suffered with (parental) physical illness and 2.3\% had problems with mental illness. The fathers of just less than 1\% of children had died and about 1-in-30 children had lost their mother due to death. Domestic tension was impacting on 4\% of children, unemployment was affecting 2.5\%, and alcoholism was thought to be a problem in just about 1-in-100 families.

The average weight at age 11 was 36.6 kilograms and the average height was 1.45 meters. Some $7.98 \%$ of children now had a physical handicap or disability compared to $3.7 \%$ at age 7 . Some $8 \%$ of children no longer had their biological father in the household and teachers assessed $22 \%$ of children as being academically outstanding. By age 16, the cohort had grown by 21 centimetres in height and gained about 20 kilograms in weight. Some 7\% of children had been in some trouble with the police by age 16, and the average log household weekly income was 3.639. The percentage of children without their biological father in the household was just under $12 \%$.

Turning to prominent contemporary socioeconomic outcomes for the cohort at age 50, we see that $14 \%$ had a degree level qualification, $70 \%$ were married, $18 \%$ reported to be in poor health, $86 \%$ had some form of employment and just over $2 \%$ reported being unemployed.

\subsection{Associations between key childhood variables and adult life satisfaction}

Figure 2 shows salient raw relationships between key childhood variables of interest and average adult life satisfaction. None of these bivariate relationships seems surprising: low birth weight, low social class of father at birth, poor teacher assessed cognitive ability at age 11, and low household income at age 16, are all associated with lower adult life satisfaction. ${ }^{6}$ In addition, being in a family that a social worker has assessed as having many difficulties at age 7, parent-assessed behavioural problems at age 7, health conditions at age 7, and teacher-assessed social maladjustment issues at age 11, are all negatively related to adult life satisfaction. Interestingly the largest raw gradients are found for number of family difficulties reported by health workers and teacher-assessed maladjustment, being associated with about a 1 and 0.7-point difference, respectively, in life satisfaction comparing the best and worse

\footnotetext{
${ }^{6}$ In Figure 2, for the attributes socioeconomic status, number of family difficulties, and number of health conditions each dot represents average life satisfaction for each unique value. In all other plots each dot represents 250 children.
} 
cases. The task of our empirical models then is to untangle the independent predictive effects of these variables, which are all to some extent correlated.

\section{Estimation Results}

\subsection{Fixed Component of adult life satisfaction}

To do this calculation we restrict the sample to only those cohort members out of the working sample for whom we observe all of the four life satisfaction measures $(n=4,400)$. For this sample, the variance of life satisfaction is 2.64, 3.21, 2.01 and 3.19 at ages 33, 42, 46 and 50, respectively. From Equation (7), using the independence in the transient factors means we can back out the fixed component to be 1.21 , or $45 \%$ of the variation in life satisfaction at age 33, 38\% at age $42,60 \%$ at age 46 and $38 \%$ at age 50 .

If the transient factors in (7) are not uncorrelated over time and there is some persistence in their effects that leads to a correlation between the transient factors, then the contribution of fixed traits would be less than calculated here because the second term would be relatively larger. Hence the values above represent the upper estimate of the amount of variation due to fixed traits. Although the NCDS does not have enough twins to be able to isolate any genetic component of life satisfaction, our estimate of the fixed component is reasonably in line with the results study by De Neve et al. (2010). In this study the authors analysed a sample of twins from the US National Longitudinal Study of Adolescent Health and estimated that one-third (33\%) of the variance in individual life satisfaction can be attributed to genetic differences. They also find that the genetic component of life satisfaction is larger for men (39\%) than women (26\%), and that the heritability of life satisfaction tends to increase with age. Our average estimates across the four points is about $45 \%$, on the lower end of the range of 44-52\% found in the widely cited twins study by Lykken and Tellegen (1996). The similarity of these estimates is interesting because since our analysis is not based on twins the fixed component that we find will likely be a mixture of genetics linked to future well-being, the environmental characteristics (or nurture aspect) that the childhood was raised in, and the complex interaction of genetics and the environment. The key question now is how much of the fixed traits are captured by the childhood variables identified in the literature as being potentially important indictors of future outcomes.

\subsection{Childhood characteristics and adult life satisfaction}

Table 2 shows the results of OLS regressions of childhood circumstances on average adult life satisfaction using the full working sample, which is a direct estimation of equation (2). In specification 
(1) we only include the variables known at birth, while in specifications (2), (3) and (4) we add the variables for age 7,11 and 16, respectively. Even though the life satisfaction responses are ordinal in nature (on a 0-10 scale), it is common in the literature to use linear models to make the interpretation of the results and comparison with other studies easier. This is because it is typically found to be the case that linear and ordinal models provide essentially the same results (see, for example, Ferrer-i-Carbonel and Frijters, 2004). Moreover, in Table 2 we are modeling average life satisfaction and consequently there are 56 observed life satisfaction values (averaged over the observed values). While we focus mainly on the OLS results we also test whether the predictability of adult life satisfaction from childhood and adolescent characteristics is much changed when ordinal models are used. Given the sequential nature of our modeling strategy in which we include in the models repeated measures of social class, health, and cognitive and non-cognitive attributes of children, we adjust the significant levels of the individual coefficients to address the issue of multiple comparisons. There are a number of proposed ways to do this, and we have utilized the method of Benjamini and Hochberg (1995). Practically, this method entails rejecting the null hypothesis of coefficient insignificance at $p$-values lower than the commonly used $10 \%$ or $5 \%$. In our context, only when the coefficients have $p$-values less than $0.5 \%$ do we consider them to be statistically significant predictors of life satisfaction.

Unlike studies that focus on establishing the causal effect of one childhood characteristic on later outcomes, using for example changes in minimum schooling leaving age of parents, or an assumed exogenous shock to the health of a parent or child, it is not possible to make strong causal statements in our context where we are interested in the role of a wide-range of childhood characteristics (in terms of the general model, finding the actual functions $g($.) is beyond the scope of the paper). Even though we are following children from birth, we can make no causal statements and discuss our results in terms of prediction and association.

Specification (1) shows that the only strongly significant predictors of adult life satisfaction known at birth are gender, low birth weight, number of older siblings and low social class of father. Boys are predicted to be 0.15 less satisfied than girls as adults, being born below normal weight is associated with a 0.23 reduction in satisfaction, and each additional older sibling is predicted to lower life satisfaction by 0.05 . Interestingly only having a father in the lowest social class (unskilled worker) is associated with a substantive lowering of adult life satisfaction (-0.33). However, we see that children with more highly educated parents are not found to be more satisfied adults. A salient aspect of this model is that only $1.2 \%$ of the total variation in adult life satisfaction is explained. 
In the second specification, the most important attributes of children measured at age 7 are added, including test scores for arithmetic, copying design, draw-a-man and reading, chronic health conditions, an index of behavioural problems and the British Social Maladjustment Guide score. Updated measures of father's occupational class and dummy indictors for health worker assessed family difficulties including financial difficulties are also included. We find that teacher assessed cognitive ability is a strongly significant predictor of future wellbeing, with more able children predicted to be more satisfied adults. Predictors capturing what are often termed non-cognitive skills are equally found to be important. Children who exhibit behavioural-emotional problems and social maladjustment are predicted to be less satisfied adults. Moving from having the least behaviouralemotional problems to the most, and from being least maladjusted to most, is associated with a 0.4-0.5 reduction in average adult life satisfaction. Therefore, if we took a child at the bottom of the teacher assessed ability score, but also with the worst outcomes for behavioural-emotional problems and social adjustment, the model would predict a substantial reduction in adult life satisfaction. However, observations of such children in the data are few. One outlier in these results is the negative coefficient on the reading test scores, for which we have no potential explanation. ${ }^{7}$

As has been more widely found in the literature, we find that a child without the biological father in the household at age 7 has worse adult outcomes, in this case a lowering of life satisfaction of 0.373. Importantly, even though the measures of major family difficulties were independently assessed, we find no significant predictive power of these variables on life satisfaction. However, the coefficients on nearly all of the substantive social problems such as mental illness, domestic tension, unemployment, alcoholism, as well as death of mother, have the expected negative sign but the number of observations for many of these problems is small. The only variable from the birth information to remain significant once age 7 information is included is gender, with the negative male result still evident (birth weight is borderline significant). We note that some of the effect of low father's social class at birth runs through the cognitive and non-cognitive attributes at age 7 , as having an unskilled father remains a significant negative predictor of life satisfaction when these attributes are excluded from specification 2. Importantly, the proportion of the variance in adult life satisfaction explained by this model, with key birth and age 7 characteristics, is only $2.8 \%$.

Specification (3) includes the main characteristics of a child at age 11 that are known, including updated measures of health, cognitive and non-cognitive attributes, number of siblings, whether or not

\footnotetext{
${ }^{7}$ If we look at the raw relationship between the reading test score and adult life satisfaction we find a positive gradient. This is also evident in the regressions models when we only include the birth characteristics. It is only when we include the other measures of cognitive and non-cognitive attributes that the sign of the reading score reverses to be negative.
} 
the biological father is in the household and father's occupational status. We also, for the first time, include child height and weight and find that heavier children are predicted to become slightly less satisfied adults. Behavioural-emotional problems and social maladjustment remain as significant negative predictors of future life satisfaction. Even conditional on these measures of non-cognitive attributes at age 7, moving from the top to the bottom of the behavioural-emotional problems index, and the social adjustment score, is associated with 0.77 and 0.97 lower life satisfaction, respectively. Children whose biological father is no longer in the household at age 11 are predicted to have a 0.26 lower average life satisfaction, but this is not strongly significant given our conservative criteria. As with the age 7 results, we still get the unexpected result that a better performance in reading is linked to reduced satisfaction. All birth variables, with the exception of gender, are insignificant in this model, but age 7 teacher measured cognitive ability remains a significant predictor. Adding age 11 characteristics increases the predictive power of the model to $4.3 \%$ of variance in adult life satisfaction.

In the final specification (4), age 16 information is added to the model. Importantly, the negative association between behavioural problems and future wellbeing remains strong. It is also interesting that teacher-assessed behaviour problems have additional predictive power over and above what parents observe about their own children. Having the worst score for both parent and teacher assessed problems is predicted to lower adult life satisfaction by 2 whole points (or 1.3 standard deviations) on the 0-10 scale even holding age 7 measures constant, which is substantially larger than has been found for any other characteristic or attribute in the typical life satisfaction regressions in the extensive literature. We also find some action from teacher assessed child personality controls, measured for the first time at age 16. However, the extent to which personality is fully determined (or fixed) by this age, or changes through an individual's lifetime is still open to debate. We find that aggressiveness, or not being timid as an adolescent, is positively related to future life satisfaction while, in contrast, being withdrawn (or less sociable) is associated with lower life satisfaction. If we again move a child from the top to the bottom of the parent and teacher-assessed behaviour problems index, and also do the same with the timid-aggressive and sociable-withdrawn personality measures, the model predicts an almost 3-point (or 2 standard deviation) lower average life satisfaction. We find no evidence that height, or weight, measured at age 16 are significant predictors of future life satisfaction. Importantly, we find no residual prediction power of parental education or father's occupational class, measured at birth, age 7 , age 11 or age 16 , in this model. We also find no significant relationship between household income observed at age 16 and future life satisfaction. This extended model, 
however, does indicate a significant long-term effect of low birth weight on adult wellbeing. The inclusion of age 16 child and family information into the model increases the R-squared value to $6.8 \%{ }^{8}$

\subsection{Further exploring the predictability of adult life satisfaction}

Figure 3 visually highlights the prediction power of the full model (specification 4). The figure shows mean life satisfaction and the 25th and 75th percentiles of observed life satisfaction for 10 groups. Each group corresponds to a decile of predicted life satisfaction: for example, observations in the first group have the lowest $10 \%$ of predicted life satisfaction values, the mean predicted life satisfaction for this group is 6.6 (x-axis), and the mean observed life satisfaction for this group is 6.5 (y-axis). The figure demonstrates three interesting features of the regression models in Table 2. First, there is significant overlap in observed life satisfaction values between those with the 'worst' childhoods (decile 1) and those with the 'best' childhoods (decile 10) - 25\% of decile 1 observations have life satisfaction values greater than mean life satisfaction for decile 10. In other words, children that are predicted to have the unhappiest lives are often happier than children that are predicted to have the happiest lives. Second, most childhoods give similar levels of adult life satisfaction - observed life satisfaction distributions for decile groups 2 to 8 are relatively similar. Third, the main benefit from a 'good' childhood is that they protect individuals from experiencing particularly unhappy lives, rather than guaranteeing life satisfaction - across decile groups, the gradient in the 25th percentile of observed life satisfaction is much steeper than the gradient in the 75th percentile of observed life satisfaction.

Another way of looking at the predictive power of childhood characteristics is shown in Table 3. To make sure that our results are not just a result of using linear models of life satisfaction, we also provide the results from an ordered probit model. ${ }^{9}$ The OLS predictions reflect the results in Figure 3, with the vast majority of predictions lying between 7 and 8, despite 715 individuals with life satisfaction $\leq 5$, 733 with life satisfaction of 6, 1,703 with life satisfaction of 9, and 615 with life satisfaction of 10. The ordered probit predictions are, if anything, worse than the OLS predictions: the ordered probit model is better at predicting particularly low scores (life satisfaction $\leq 5$ ), but places far too much weight on scores of 8. In summary, Table 3 shows that, with the observed childhood variables included in our models, we are unable to accurately identify the individuals that will have low life satisfaction $(\leq 6)$ and high life satisfaction $(\geq 9)$. Moreover, this fact is not dependent upon the estimation method used to form the predictions.

\footnotetext{
8 The low R-squared result also holds if we restrict the sample to individuals for whom we observe all of the four life satisfaction measures, as used in sub-section 4.1 .

${ }^{9}$ The full results from the ordered probit model are available on request.
} 
We have already calculated that the total contribution of fixed traits to the variance in life satisfaction is around $45 \%$. Therefore, the roughly $7 \%$ of the total variation we have found to be explained by childhood and family characteristics implies that these factors pick up only about $16 \%$, or one-sixth, of the fixed component that exists. Five-sixths of the effect of fixed traits is, therefore, not captured by the extensive variables we include in the models, which are often focused on by economists as being key predictors of adult outcomes.

\subsection{Adult life characteristics, lagged life satisfaction and life satisfaction at age 50}

Table 4 shows the OLS regression results for life satisfaction at age 50, taking the same specification as in the full model presented in Table 2, but now including contemporaneous key socioeconomic variables and then long lags of life satisfaction. This corresponds to equation (2). The sample is reduced by around 2,000 observations that do not have age 50 life satisfaction values.

As expected given the findings of the life satisfaction literature, adding the important contemporaneous (age 50) measures of socioeconomic status in the form of health, marital status, education, employment status and wages significantly improves the fit of the model. The inclusion of these variables adds around $12 \%$ to the explained variation (from $5.4 \%$ to $17.4 \%$ ). Someone in poor health at age 50 has a contemporaneous life satisfaction reduction of 1.08 lower, whilst someone employed has a 0.546 higher life satisfaction compared to a non-participant. Marriage adds 0.777 to life satisfaction whilst a 1-point higher log wage is associated with a higher life satisfaction of 0.265. Therefore, the contemporaneous association between socioeconomic variables and life satisfaction remains strong, even when we control for extensive childhood and early family characteristics.

In the third to fifth specifications we incrementally include the long lags of life-satisfaction, and find that we roughly double the predictive power of the model (37\%) over specification 2. As might be expected, the more recent (age 46) the measure of life satisfaction, the stronger is the relationship with current life satisfaction (age 50). We can again calculate the percentage of the total variation in life satisfaction that is due to fixed factors and random factors by applying equation (7) and assuming that the random error terms are completely uncorrelated between ages (a strong assumption we agree). If we consider the contribution of circumstances at age 50 as 'neutral' and therefore assign it neither to fixedtraits nor to completely chance factors, then Table 4 indicates that the total contribution of childhood factors and lags of life satisfaction to the variance explained is $0.316\left(=\mathrm{R}^{2}\right.$ minus the partial- $\mathrm{R}^{2}$ of the circumstances at age 50). This is lower than the $40 \%$ obtained by equation (6) which can be due either to the fact that the full effect of all childhood circumstances is not encapsulated in the lags of life 
satisfaction and the observable childhood characteristics, or due to the fact that the direct application of (6) overstates the degree to which childhood factors explain life satisfaction because it implicitly excludes slowly changing factors.

We therefore find additional evidence that fixed traits explain no more than about 30-40\% of total variance in adult life satisfaction, and this is making conservative assumptions. As soon as we allow for more persistent effects of contemporaneous unobservables (which seems plausible given the higher relation between life satisfaction at age 50 and age 46 than at age 42 and 33), then the true importance of fixed traits could be considerably lower.

\subsection{The predictability of other adult outcomes in the NCDS}

Using the childhood and family characteristics at birth, age 7, age 11 and age 16, we investigate whether the low predictability of average adult life satisfaction from a wide-range of childhood and family characteristics (R-squared $=0.054$, see Table 4) differs from that of other life outcomes measured at age 50 in the NCDS that are commonly focused on in the literature. We find that the highest R-squared values are found for holding a degree level qualification (0.32) and log wages (0.27), but they are much lower for being employed (0.08), reporting to be in poor health (0.08) and being married (0.04). In this light, the results for life satisfaction that we present appear to be plausible. ${ }^{10}$

\section{Repeating the analysis using the 1970 British Cohort Study}

To test the robustness of the main results we can perform the same type of analyse using data from the BC70. ${ }^{11}$ The cohort consists of all children born in England, Scotland and Wales in one particular week in April 1970. The size of this cohort is very similar to the NCDS, with around 17,200 children. Information on this cohort is currently available at birth, age 5 (1975), age 10(1980), age 16 (1986), age 26 (1996), age 29 1999/00), age 34 (2004/05) and age 38 (2008/09). A key aspect of the BC70 for our purposes is that childhood information on cognitive and non-cognitive attributes is collected two years earlier (at age 5) than in the NCDS (age 7). Additionally, information on the personality traits of children is collected earlier, at age 10, rather than at age 16 in the NCDS. Life satisfaction information was collected at ages 29, 34 and 38. We focus here on the prediction power of early life characteristics, those observed at birth, age 5 and age 10, for life satisfaction averaged over ages 29, 34 and 38. We use the similar sets of control variables for each age as for the NCDS analyses. We find that birth

\footnotetext{
10 The full estimates are available on request.

${ }^{11}$ We do not provide the full results BC70 results in the paper. They are available on request.
} 
characteristics explain about $2.1 \%$ of the variability in adult life satisfaction, increasing to $3.5 \%$ when age 5 data are added, and $4.8 \%$ when age 10 characteristics are included. The results therefore are very close to those from the NCDS. As with the NCDS, the strong predictive power of early behavioural problems (whether measured at age 5 or 10) is clearly evident in the results. For example, moving from the top to the bottom of the behavioural problems scale at age 10 is associated with a 0.63 lower level of adult satisfaction, with a negative residual effect of age 5 problems of 0.40 remaining. Personality measured in the BC70 at age 10 is also important, especially the detrimental effect of being a very introverted child (-0.34). We also find that mother's mental health, captured through the malaise score, is a significant and substantive predictor of children's future life satisfaction. As with the NCDS we find no evidence of strong significant relationship between conventional socioeconomic characteristics, namely social class or parental education, and child later life satisfaction, controlling for age 5 or 10 characteristics.

\section{Conclusions}

In this paper we contribute to the literature on life satisfaction and happiness, and also the literature on the importance of childhood circumstances in explaining adult outcomes. We analyse data from the UK’s National Child Development Study (NCDS) that has followed children born in March 1958 until age 50, and test the robustness of our main results using data from the 1970 British Cohort Study (BC70). We have addressed the question of how well adult life satisfaction is predicted by a comprehensive list of childhood circumstances, including conventional measures of family social class, health, personality, and cognitive and non-cognitive attributes. Contrary to what we expected when we started the research, we have found that no more than $2 \%$ of the variation in averaged adult life satisfaction (observed at ages 33, 42, 46, and 50, in the NCDS) can be predicted by characteristics at the time of birth, including birth weight, gestation period, and conventional measures of economic status measured by parental education and father's occupational class. When we additionally include extensive controls for age 7, 11 and 16 characteristics, which include a wide-range of child-specific traits and family characteristics, the predictive power increases to only 7\%. This lack of predictive power result is robust to the use of both linear and ordinal models of life satisfaction. This finding is also essentially replicated using data from the 1970 British Cohort Study.

We have estimated the relative importance of fixed versus transient factors in explaining life satisfaction, and found that transient factors dominate: at best, $30 \%$ to $40 \%$ of the variation in life satisfaction can be attributed to fixed factors and only one-sixth of that is captured by what we measure 
during childhood and adolescence. Some $60 \%$ to $70 \%$ are due to transient factors, of which only about $10 \%$ is captured by current measures of education, marriage, income, employment and health. Another way of putting this is that, knowing childhood and family characteristics at birth, age 7, age 11 and 16, together with long lags of life satisfaction (measured at ages 33, 42 and 46) and contemporaneous measures of socioeconomic status, enables us to predict only $36 \%$ of the variation in life satisfaction observed at age 50 .

Despite the overall low predictive power, the individual childhood characteristics we find that are correlated with adult life satisfaction are intuitively plausible and in line with recent research on the importance of non-cognitive attributes and personality. The main findings are:

- Boys are predicted to have lower life satisfaction than girls (7\% of a standard deviation);

- Low birth weight is predicted to lower adult life satisfaction (15\% of a standard deviation);

- Conventional family social status measures such as parental education and occupational class of father are not strong predictors of a child's future life satisfaction;

- Non-cognitive skills, captured by parent and teacher-assessed behavioural problems, are strong predictors of adult life satisfaction whether measured at age 7, 11 or 16. Comparing the best to the worse non-cognitive skills at age 16 is predicted to lower average life satisfaction by 1 point (66\% of a standard deviation);

- Personality traits, evaluated by teachers when the child was 16 in the NCDS, or age 10 in the BC70, are significant predictors of future wellbeing. Children who are more timid and less sociable (in the NCDS), or more introverted (in the BC70) are predicted to be less satisfied adults. Comparing the top and bottom of these personality traits in the NCDS is predicted to lower life satisfaction by about 0.7 (47\% of a standard deviation).

We can evaluate these results in three main ways. First, we can point to the factors that predict life satisfaction and investigate them further to see how policy is affecting them. Secondly, we can note the apparent importance of transient and strongly persistent factors that are not determined by childhood as evidence that there is a fair degree of equality of opportunity to have a satisfied life in the UK for these cohorts: many of the individuals that look like they are going to lead an unsatisfied life nevertheless turn out to have been successful in their pursuit of wellbeing. Finally, these results tell us we have further to go to understand the factors that drive life satisfaction, given that the wide-ranging childhood characteristics we include in our models predict less than $10 \%$ of the variation in adult life 
satisfaction. Perhaps most importantly for the economic understanding of happiness is that socioeconomic characteristics when young have little overall explanatory power for later life satisfaction. The results therefore suggest that the importance of economic variables is to some extent not working via childhood but rather by affecting adults independently of their childhood circumstances.

There are a number of caveats to our study. Firstly, given that we have focused on a wide-range of childhood characteristics in predicting future life satisfaction, we are unable to make any causal statements. For example, we are not able to identify the pathways by which early behavioural problems are linked to future life satisfaction. Secondly, there are hundreds of potential variables and childhood characteristics collected in both the NCDS and BC70, and we have had to be selective about which variables to include as predictors in order to make our models tractable. In this respect we have based our selection on the main childhood characteristics identified in the economics literature over the last few decades, and we will therefore not have fully captured all the potential predictors of adult life satisfaction potentially available in the surveys. Thirdly, the two cohort studies we use, following individuals over many years, suffer from a large amount of attrition. Therefore we need to be cautious about the extent to which our findings can be generalised to the whole cohort. Finally, the results in this paper apply to children born in very different times (1958 or 1970), and they may be different for more recent birth cohorts. However, we will have to wait several decades before we can test if this is the case, for example, looking at the children in the Millennium Cohort Study (born in 2000/01), as they become adults.

\section{References}

Ahlburg, D. (1998). Intergenerational transmission of health. American Economic Review, Papers and Proceedings, 88, pp. 265-270.

Almlund, M., Duckworth, A., Heckman, JJ. and Kautz, T. (2011). Personality psychology and economics. IZA Discussion Paper no. 5500, Bonn, February.

Benjamini, Y. and Hochberg, Y. (1995). Controlling for false discovery rate: A practical and powerful approach to multiple testing. Journal of the Royal Statistical Society, Series B, 57, pp. 289-300.

Black, S., Devereux, P. and Salvanes, K. (2007). From the cradle to the labor market. Quarterly Journal of Economics, 122, pp. 409-39.

Blanchflower, DG. and Oswald, AJ. (1998). What makes an entrepreneur? Journal of Labor Economics, 16, pp. 26-60.

Blanden, J., Gregg, P. and Macmillan, L. (2007). Explaining intergenerational income persistence: Noncognitive skills, ability and education. Economic Journal, 117, pp. c43-60. 
Borghans, L., Duckworth, AL., Heckman, JJ. and Weel ter, B. (2008). The economics and psychology of personality traits. Journal of Human Resources, 43, pp. 972-1059.

Carneiro, P., Crawford, C. and Goodman, A. (2007). The impact of early cognitive and non-cognitive skills on later outcomes. Centre for the Economics of Education, London School of Economics.

Case, A., Fertig, A. and Paxson, C. (2005). The lasting impact of childhood health and circumstance. Journal of Health Economics, 24, pp. 365-89.

Clark, AE., Frijters, P. and Shields, MA. (2008a). Relative income, happiness and utility: An explanation for the Easterlin Paradox and other puzzles. Journal of Economic Literature, 46, pp. 95-144.

Clark, A., Diener, E., Georgellis, Y. and. Lucas, R. (2008b). Lags and leads in life satisfaction: A test of the baseline hypothesis. Economic Journal, 118, pp. F222-243.

Conti, G. and Heckman, JJ. (2010). Understanding the early origins of the education-health gradient: A framework that can also be applied to analyse gene-environment interactions. Perspectives on Psychological Science, 5, pp. 585-605.

Contoyannis, P. and Dooley, M. (2010). The role of child health and economic status in educational, health and labor market outcomes in young adulthood. Canadian Journal of Economics, 43, pp. 323-346.

Cunha, F. and Heckman, J.J. (2008). Formulating, identifying and estimating the technology of cognitive and noncognitive skill formation. Journal of Human Resources, 43, pp. 738-782

Cunha, F., Heckman, J. and Shennach, S. (2010). Estimating the technology of cognitive and non-cognitive skill formation. Econometrica, 78, pp. 883-931.

Currie. J. (2009). Healthy, wealthy, and wise: Socioeconomic status, poor heath in childhood, and human capital development. Journal of Economic Literature, 47, pp. 87-122.

Currie, J. (2011). Inequality at birth: Some cases and consequences. American Economic Review, Papers and Proceedings, 101, pp. 1-22.

Currie, J., Stabile, M., Manivong, P. and Roos, LL. (2010). Child health and young adult outcomes. Journal of Human Resources, 45, pp. 517-548.

Currie, J. and Thomas, D. (1995). Does Head Start make a difference? American Economic Review, 85, pp. 341364.

Currie, J. and Thomas, D. (1999). Does Head Start help Hispanic children? Journal of Public Economics, 74, pp. 235-62.

De Neve, JE., Christakis, NA., Fowler, JH. and Frey, BS. (2010). Genes, economics, and happiness. Working Paper 2010-24, Center for Research in Economics, Management and the Arts (CREMA), Basel.

Di Tella, R. and MacCulloch, R. (2006). Some uses of happiness data in economics. Journal of Economic Perspectives, 20, pp. 25-46. 
Dolan, P., Peasgood, T. and White, M. (2008). Do we really know what makes us happy? A review of the economic literature on the factors associated with subjective well-being. Journal of Economic Psychology, 29, pp. 94-122.

Dolan, P., Layard, R. and Metcalfe, R. (2011). Measuring subjective well-being for public policy. Office for National Statistics, London, UK.

Ferrer-i-Carbonel, A. and Frijters, P. (2004). The effect of methodology on the determinants of happiness. Economic Journal, 114, pp. 641-659.

Field, F. (2010). The Foundation Years: Preventing Poor Children becoming Poor Adults: The Report on the Independent Review on Poverty and Life Chances. HM Government, London.

Frey, BS. And Stutzer, A. (2002). What can economists learn from happiness research? Journal of Economic Literature, 40, pp. 402-435.

Frijters, P., Hatton, T. and Shields, MA. (2010). Childhood economic conditions and length of life: Evidence from the UK Boyd Orr Cohort, 1937-2005. Journal of Health Economics, 29, pp. 39-47.

Frijters, P., Johnston, DW. and Shields, MA. (2011). Happiness dynamics with quarterly events data. Scandinavian Journal of Economics, 113, pp. 190-211.

Fujita, F. and Diener, E. (2005). Life satisfaction set point: Stability and change. Journal of Personality and Social Psychology, 88, pp. 158-164.

Goodman, A., Joyce, R. and Smith, JP. (2011). The long shadow cast by childhood physical and mental problems on adult life. Proceedings of the National Academy of Sciences, 108, pp. 6032-37.

Heady, B. and Wearing, AJ. (1992). Understanding happiness: A theory of subjective well-being. Longman Cheshire, Melbourne.

Heckman, JJ. (2011). The American family in Black and White. A post-racial strategy for improving skills to promote equality. IZA Discussion Paper no. 5495, February.

Heckman, JJ., Stixrud, J. and Urzua, S. (2006). The effects of cognitive and noncognitive abilities on labor market outcomes and social behavior. Journal of Labor Economics, pp. 411-482.

Heckman, JJ., Hyeok Moon, S., Pinto, R., Savelyev, PA. and Yavitz, A. (2010). The rate of return to the HighScope Perry Preschool Program. Journal of Public Economics, 94, pp. 114-128.

Holmlund, H., Lindahl, M. and Plug, E. (2011). The causal effect of parents' schooling on children's schooling. Journal of Economic Literature, forthcoming.

Layard, R. (2005). Happiness: Lessons from a New Science. Penguin, London.

Lucas, R., Clark, A., Diener, E. and Georgellis, Y. (2003). Re-examining adaptation and the setpoint model of happiness: Reaction to changes in marital status. Journal of Personality and Social Psychology, 84, pp. 527-539.

Lucas, R., Clark, A., Georgellis, Y. and Diener, E. (2004). Unemployment alters the set-point for life satisfaction. Psychological Science, 15, pp. 8-13. 
Lykken, DT. (1999). Happiness: What studies on twins show us about nature, nurture, and the happiness set point. New York: Golden Books.

Lykken, DT. and Tellegen, A. (1996). Happiness is a stochastic phenomenon. Psychological Science, 7, pp. 186189.

McLeod, J. and Kaiser, K. (2004). Childhood emotional and behavioural problems and educational attainment. American Sociological Review, 69, pp. 636-58.

Mensah, FK. And Hobcraft, J. (2008). Childhood deprivation, health and development: Associations with adult health in the 1958 and 1970 British prospective birth cohort studies. Journal of Epidemiology and Community Health, 62, pp. 599-606.

Myers, DG. and Diener, E. (1995). Who is happy? Psychological Science, 6, pp. 10-19.

Salm, M. and Schunk, D. (2011). The relationship between child health, developmental gaps, and parental education: Evidence from administrative data. Journal of the European Economic Association, forthcoming.

Smith. J. (2009). The impact of childhood health on adult labor market outcomes. Review of Economics and Statistics, 91, pp. 478-489.

Weiss, A., Bates, TC. and Luciano, M. (2008). Happiness is a personal(ity) thing: The genetics of personality and well-being in a representative sample. Psychological Science, 19, pp. 205-10. 
FIGURE 1: Life Satisfaction Distributions in the NCDS

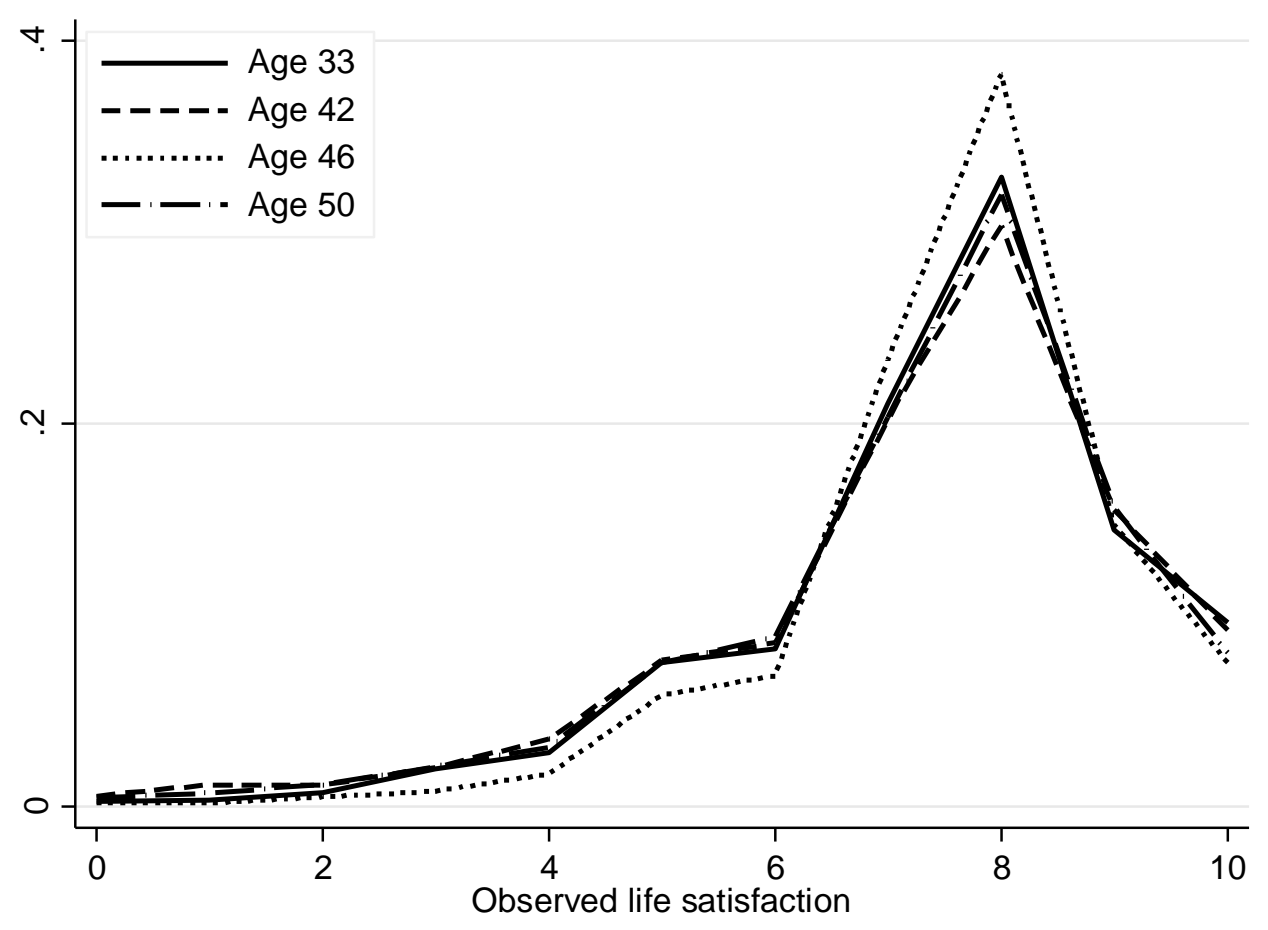


FIGURE 2: Raw Relationships between Childhood Circumstance and Average Adult Life Satisfaction
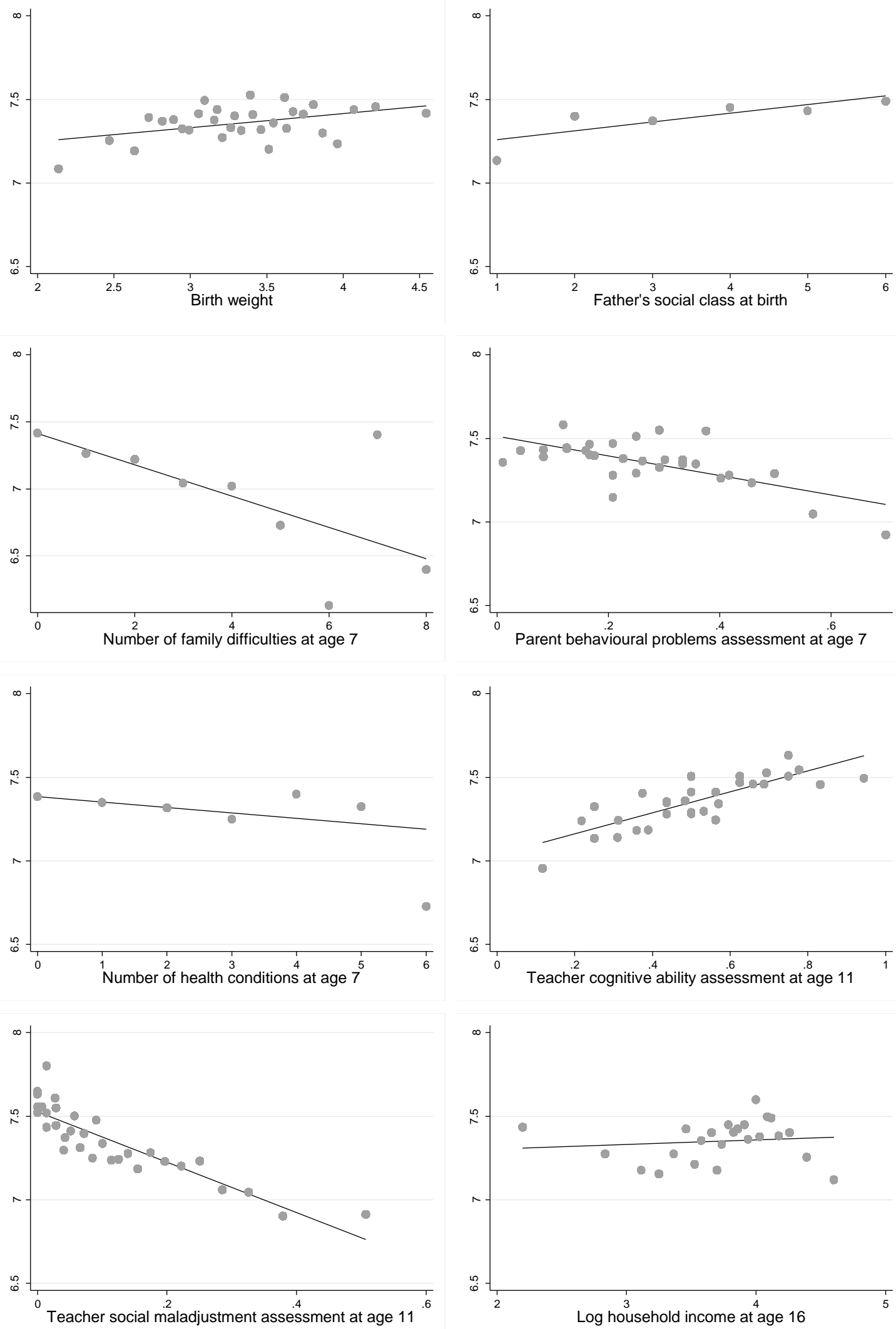
FIGURE3: Within Sample Predictive Power of Childhood Circumstance for Adult Life Satisfaction

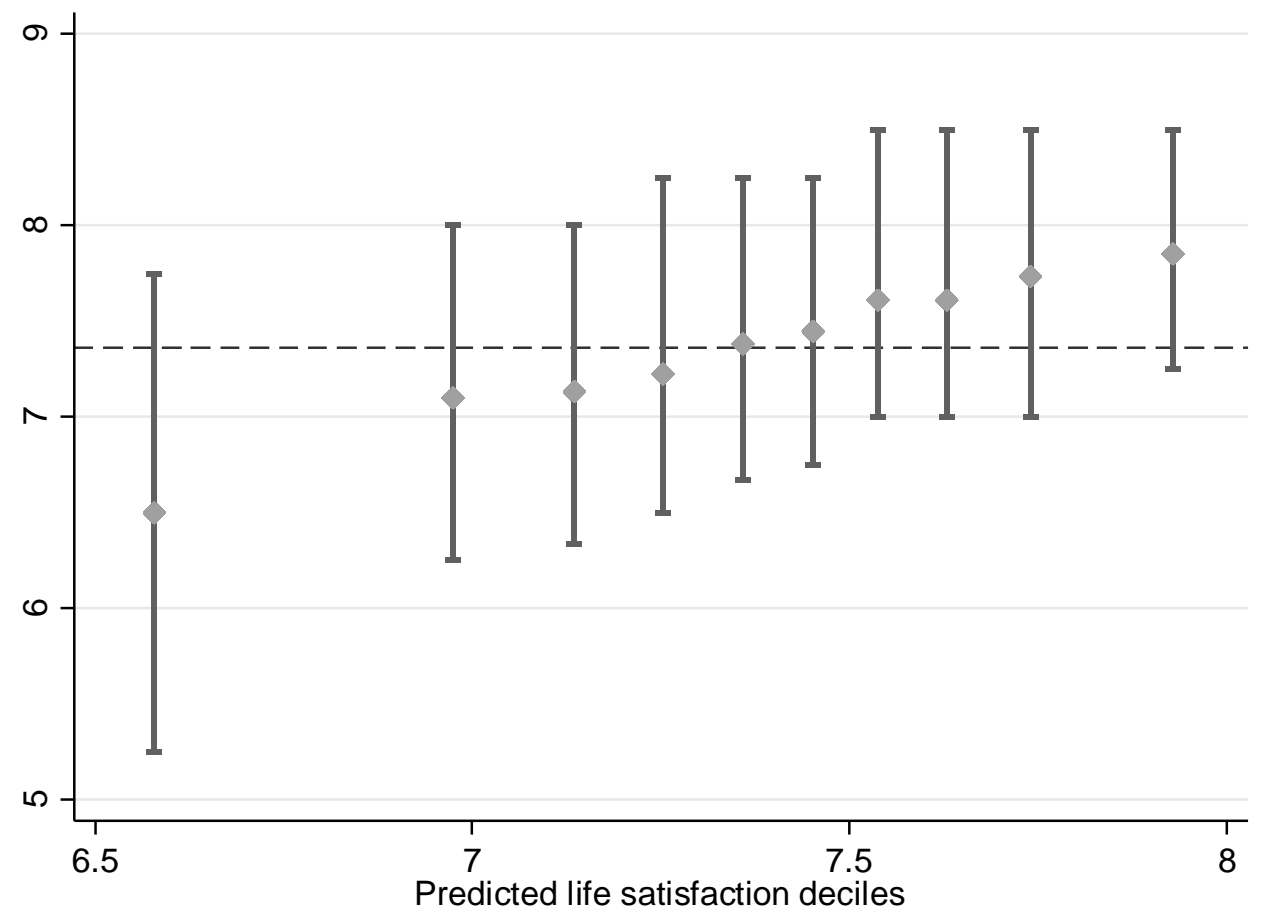


TABLE 1: Summary Statistics

\begin{tabular}{|c|c|c|c|c|}
\hline & Mean & SD & Min & Max \\
\hline \multicolumn{5}{|l|}{ Life Satisfaction } \\
\hline Age 33 & 7.435 & 1.727 & 0 & 10 \\
\hline Age 42 & 7.301 & 1.915 & 0 & 10 \\
\hline Age 46 & 7.584 & 1.481 & 0 & 10 \\
\hline Age 50 & 7.325 & 1.829 & 0 & 10 \\
\hline Mean over observed ages & 7.359 & 1.490 & 0 & 10 \\
\hline \multicolumn{5}{|l|}{ Information at birth } \\
\hline Cohort member is male & 0.496 & 0.500 & 0 & 1 \\
\hline Mother smoked during pregnancy & 0.325 & 0.468 & 0 & 1 \\
\hline Gestation (weeks) & 40.146 & 1.777 & 27 & 49 \\
\hline Labour induced & 0.134 & 0.340 & 0 & 1 \\
\hline Method of delivery was caesarean & 0.027 & 0.162 & 0 & 1 \\
\hline Abnormality during pregnancy & 0.269 & 0.443 & 0 & 1 \\
\hline Low birth weight & 0.057 & 0.231 & 0 & 1 \\
\hline Number of siblings & 1.240 & 1.479 & 0 & 9 \\
\hline Mother's age & 27.577 & 5.669 & 14 & 47 \\
\hline Mother stayed in school after minimum age & 0.257 & 0.437 & 0 & 1 \\
\hline Mother single & 0.030 & 0.171 & 0 & 1 \\
\hline Father's age & 30.703 & 6.324 & 16 & 78 \\
\hline Father stayed in school after minimum age & 17.664 & 2.901 & 14 & 39 \\
\hline Father's age left education if not minimum & 0.233 & 0.423 & 0 & 1 \\
\hline Father semi-professional worker & 0.136 & 0.343 & 0 & 1 \\
\hline Father non-manual skilled worker & 0.099 & 0.299 & 0 & 1 \\
\hline Father manual skilled worker & 0.515 & 0.500 & 0 & 1 \\
\hline Father semi-skilled worker & 0.119 & 0.324 & 0 & 1 \\
\hline Father unskilled worker & 0.087 & 0.282 & 0 & 1 \\
\hline \multicolumn{5}{|l|}{ Information at age 7} \\
\hline Number of siblings & 2.081 & 1.564 & 0 & 12 \\
\hline Number of chronic health conditions & 0.515 & 0.881 & 0 & 17 \\
\hline Any physical handicap / disabling condition & 0.037 & 0.190 & 0 & 1 \\
\hline Behavioural-emotional problems index & 0.260 & 0.149 & 0 & 1 \\
\hline British Social Adjustment Guide total score & 0.127 & 0.130 & 0 & 1 \\
\hline Teacher assessment of cognitive ability & 0.504 & 0.179 & 0 & 1 \\
\hline Arithmetic test score & 0.522 & 0.244 & 0 & 1 \\
\hline Copying designs test score & 0.592 & 0.164 & 0 & 1 \\
\hline Draw-a-man test score & 0.454 & 0.132 & 0 & 1 \\
\hline Southgate group reading test score & 0.797 & 0.225 & 0 & 1 \\
\hline Mother worked before child at school & 0.271 & 0.444 & 0 & 1 \\
\hline Biological father not in household & 0.058 & 0.233 & 0 & 1 \\
\hline Family difficulties - housing & 0.054 & 0.225 & 0 & 1 \\
\hline Family difficulties - financial & 0.059 & 0.235 & 0 & 1 \\
\hline Family difficulties - physical illness & 0.041 & 0.198 & 0 & 1 \\
\hline Family difficulties - mental illness & 0.023 & 0.151 & 0 & 1 \\
\hline Family difficulties - death of father & 0.008 & 0.088 & 0 & 1 \\
\hline Family difficulties - death of mother & 0.004 & 0.065 & 0 & 1 \\
\hline Family difficulties - domestic tension & 0.040 & 0.195 & 0 & 1 \\
\hline Family difficulties - unemployment & 0.025 & 0.156 & 0 & 1 \\
\hline Family difficulties - alcoholism & 0.008 & 0.089 & 0 & 1 \\
\hline Father semi-professional worker & 0.150 & 0.357 & 0 & 1 \\
\hline Father non-manual skilled worker & 0.103 & 0.304 & 0 & 1 \\
\hline Father manual skilled worker & 0.456 & 0.498 & 0 & 1 \\
\hline Father semi-skilled worker & 0.178 & 0.383 & 0 & 1 \\
\hline Father unskilled worker & 0.059 & 0.235 & 0 & 1 \\
\hline
\end{tabular}


TABLE 1: (continued)

\begin{tabular}{|c|c|c|c|c|}
\hline \multicolumn{5}{|l|}{ Information at age 11} \\
\hline Number of siblings & 2.022 & 1.533 & 0 & 8 \\
\hline Height (meters) & 1.444 & 0.071 & 1.194 & 1.727 \\
\hline Weight (kilograms) & 36.622 & 7.253 & 19.958 & 84.823 \\
\hline Any physical handicap / disabling condition & 0.079 & 0.270 & 0 & 1 \\
\hline Behavioural-emotional problems index & 0.240 & 0.134 & 0 & 1 \\
\hline British Social Adjustment Guide total score & 0.112 & 0.122 & 0 & 1 \\
\hline Teacher assessment of cognitive ability & 0.510 & 0.185 & 0 & 1 \\
\hline Teacher assesses child as outstanding & 0.222 & 0.415 & 0 & 1 \\
\hline General ability test score & 0.563 & 0.198 & 0 & 1 \\
\hline Reading comprehension test score & 0.469 & 0.175 & 0 & 1 \\
\hline Mathematics test score & 0.436 & 0.255 & 0 & 1 \\
\hline Copying designs test score & 0.698 & 0.116 & 0 & 1 \\
\hline Biological father not in household & 0.081 & 0.273 & 0 & 1 \\
\hline Father semi-professional worker & 0.189 & 0.391 & 0 & 1 \\
\hline Father non-manual skilled worker & 0.098 & 0.297 & 0 & 1 \\
\hline Father manual skilled worker & 0.436 & 0.496 & 0 & 1 \\
\hline Father semi-skilled worker & 0.169 & 0.375 & 0 & 1 \\
\hline Father unskilled worker & 0.054 & 0.226 & 0 & 1 \\
\hline \multicolumn{5}{|l|}{ Information at age 16} \\
\hline Number of siblings & 2.356 & 1.751 & 0 & 14 \\
\hline Height (meters) & 1.657 & 0.085 & 1.340 & 1.960 \\
\hline Weight (kilograms) & 56.822 & 9.608 & 27.900 & 114.100 \\
\hline Behavioural-emotional problems index - parent & 0.132 & 0.115 & 0 & 1 \\
\hline Behavioural-emotional problems index - teacher & 0.086 & 0.119 & 0 & 1 \\
\hline Teacher assessment of cognitive ability & 0.509 & 0.268 & 0 & 1 \\
\hline Reading comprehension test score & 0.740 & 0.190 & 0 & 1 \\
\hline Mathematics test score & 0.427 & 0.225 & 0 & 1 \\
\hline Personality - cautious to impulsive & 0.441 & 0.225 & 0 & 1 \\
\hline Personality - moody to even-tempered & 0.635 & 0.300 & 0 & 1 \\
\hline Personality - timid to aggressive & 0.485 & 0.191 & 0 & 1 \\
\hline Personality - flexible to rigid & 0.443 & 0.198 & 0 & 1 \\
\hline Personality - sociable to withdrawn & 0.343 & 0.258 & 0 & 1 \\
\hline Personality - lazy to hardworking & 0.572 & 0.304 & 0 & 1 \\
\hline Trouble with the police & 0.076 & 0.265 & 0 & 1 \\
\hline Biological father not in household & 0.119 & 0.323 & 0 & 1 \\
\hline Father semi-professional worker & 0.209 & 0.407 & 0 & 1 \\
\hline Father non-manual skilled worker & 0.097 & 0.296 & 0 & 1 \\
\hline Father manual skilled worker & 0.450 & 0.498 & 0 & 1 \\
\hline Father semi-skilled worker & 0.143 & 0.351 & 0 & 1 \\
\hline Father unskilled worker & 0.048 & 0.214 & 0 & 1 \\
\hline Log household weekly income & 3.639 & 0.650 & 0.693 & 4.939 \\
\hline \multicolumn{5}{|l|}{ Adult information (at age 50) } \\
\hline Log wages & 2.185 & 0.484 & 0.693 & 6.522 \\
\hline Employed & 0.857 & 0.350 & 0 & 1 \\
\hline Unemployed & 0.021 & 0.144 & 0 & 1 \\
\hline Married & 0.692 & 0.462 & 0 & 1 \\
\hline Poor health & 0.178 & 0.383 & 0 & 1 \\
\hline Degree & 0.141 & 0.349 & 0 & 1 \\
\hline
\end{tabular}


TABLE 2: Childhood Predictors of Mean Adult Life Satisfaction for a Cohort of British Children born in 1958

\begin{tabular}{|c|c|c|c|c|c|c|c|c|}
\hline & \multicolumn{2}{|c|}{ (1) } & \multicolumn{2}{|c|}{ (2) } & \multicolumn{2}{|c|}{ (3) } & \multicolumn{2}{|c|}{ (4) } \\
\hline & $\boldsymbol{\beta}$ & $t$-stat & $\beta$ & $t$-stat & $\boldsymbol{\beta}$ & $t$-stat & $\bar{\beta}$ & $t$-stat \\
\hline \multicolumn{9}{|l|}{ Information at birth } \\
\hline Cohort member is male & -0.146 & $(-4.39)$ & -0.130 & $(-3.81)$ & -0.102 & $(-2.93)$ & -0.100 & $(-2.29)$ \\
\hline Mother smoked during pregnancy & -0.060 & $(-1.67)$ & -0.028 & $(-0.77)$ & -0.010 & $(-0.27)$ & 0.007 & $(0.20)$ \\
\hline Gestation (weeks) & 0.002 & $(0.16)$ & -0.001 & $(-0.06)$ & 0.001 & $(0.11)$ & 0.002 & $(0.19)$ \\
\hline Labour induced & 0.034 & $(0.69)$ & 0.036 & $(0.73)$ & 0.039 & $(0.80)$ & 0.039 & $(0.79)$ \\
\hline Method of delivery was caesarean & -0.069 & $(-0.66)$ & -0.072 & $(-0.69)$ & -0.086 & $(-0.83)$ & -0.092 & $(-0.89)$ \\
\hline Abnormality during pregnancy & -0.008 & $(-0.21)$ & 0.006 & $(0.16)$ & 0.014 & $(0.36)$ & 0.013 & $(0.34)$ \\
\hline Low birth weight & -0.226 & $(-2.94)$ & -0.187 & $(-2.43)$ & -0.203 & $(-2.63)$ & -0.215 & $(-2.82)$ \\
\hline Number of siblings & -0.046 & $(-3.36)$ & -0.023 & $(-1.20)$ & -0.018 & $(-0.91)$ & -0.013 & $(-0.64)$ \\
\hline Mother's age & 0.002 & $(0.44)$ & -0.003 & $(-0.56)$ & -0.004 & $(-0.76)$ & -0.006 & $(-1.18)$ \\
\hline Mother stayed in school after minimum age & -0.020 & $(-0.47)$ & -0.051 & $(-1.18)$ & -0.061 & $(-1.41)$ & -0.082 & $(-1.92)$ \\
\hline Mother single & -0.185 & $(-1.01)$ & -0.015 & $(-0.08)$ & 0.049 & $(0.26)$ & 0.105 & $(0.56)$ \\
\hline Father's age & -0.001 & $(-0.24)$ & -0.001 & $(-0.13)$ & 0.000 & $(0.04)$ & 0.002 & $(0.41)$ \\
\hline Father stayed in school after minimum age & 0.054 & $(0.35)$ & 0.067 & $(0.43)$ & 0.057 & $(0.37)$ & 0.019 & $(0.13)$ \\
\hline Father's age left education if not minimum & -0.005 & $(-0.51)$ & -0.008 & $(-0.85)$ & -0.007 & $(-0.84)$ & -0.005 & $(-0.61)$ \\
\hline Father semi-professional worker & -0.065 & $(-0.67)$ & -0.052 & $(-0.50)$ & -0.059 & $(-0.57)$ & -0.034 & $(-0.32)$ \\
\hline Father non-manual skilled worker & -0.052 & $(-0.50)$ & -0.004 & $(-0.03)$ & -0.017 & $(-0.15)$ & 0.005 & $(0.04)$ \\
\hline Father manual skilled worker & -0.119 & $(-1.26)$ & -0.059 & $(-0.56)$ & -0.048 & $(-0.45)$ & -0.005 & $(-0.05)$ \\
\hline Father semi-skilled worker & -0.079 & $(-0.75)$ & 0.004 & $(0.03)$ & 0.019 & $(0.16)$ & 0.061 & $(0.53)$ \\
\hline Father unskilled worker & -0.327 & $(-2.98)$ & -0.220 & $(-1.81)$ & -0.210 & $(-1.71)$ & -0.162 & $(-1.32)$ \\
\hline \multicolumn{9}{|l|}{ Information at age 7} \\
\hline Number of siblings & - & - & -0.007 & $(-0.46)$ & -0.001 & $(-0.06)$ & -0.001 & $(-0.03)$ \\
\hline Number of chronic health conditions & - & - & -0.002 & $(-0.12)$ & 0.003 & $(0.17)$ & 0.008 & $(0.38)$ \\
\hline Any physical handicap / disabling condition & - & - & -0.074 & $(-0.81)$ & -0.056 & $(-0.61)$ & -0.043 & $(-0.47)$ \\
\hline Behavioural-emotional problems index & - & - & -0.388 & $(-3.31)$ & -0.012 & $(-0.09)$ & 0.119 & $(0.91)$ \\
\hline British Social Adjustment Guide total score & - & - & -0.498 & $(-3.32)$ & -0.212 & $(-1.38)$ & -0.074 & $(-0.48)$ \\
\hline Teacher assessment of cognitive ability & - & - & 0.570 & (3.95) & 0.570 & (3.66) & 0.497 & (3.21) \\
\hline Arithmetic test score & - & - & 0.189 & $(2.16)$ & 0.133 & $(1.49)$ & 0.124 & $(1.39)$ \\
\hline Copying designs test score & - & - & 0.052 & $(0.45)$ & -0.079 & $(-0.67)$ & -0.090 & $(-0.77)$ \\
\hline Draw-a-man test score & - & - & -0.251 & $(-1.75)$ & -0.294 & $(-2.02)$ & -0.304 & $(-2.10)$ \\
\hline Southgate group reading test score & - & - & -0.333 & $(-3.19)$ & -0.352 & $(-3.22)$ & -0.314 & $(-2.88)$ \\
\hline Mother worked before child at school & - & - & 0.025 & $(0.66)$ & 0.020 & $(0.53)$ & 0.016 & $(0.43)$ \\
\hline Biological father not in household & - & - & -0.373 & $(-3.51)$ & -0.190 & $(-1.41)$ & -0.200 & $(-1.49)$ \\
\hline
\end{tabular}


TABLE 2: (Continued)

\begin{tabular}{|c|c|c|c|c|c|c|c|c|}
\hline \multicolumn{9}{|l|}{ Information at age 7 (continued) } \\
\hline Family difficulties - housing & - & - & 0.005 & $(0.06)$ & 0.023 & $(0.27)$ & 0.058 & $(0.68)$ \\
\hline Family difficulties - financial & - & - & 0.052 & $(0.52)$ & 0.076 & $(0.77)$ & 0.100 & $(1.01)$ \\
\hline Family difficulties - physical illness & - & - & 0.004 & $(0.04)$ & 0.036 & $(0.36)$ & 0.005 & $(0.05)$ \\
\hline Family difficulties - mental illness & - & - & -0.117 & $(-0.90)$ & -0.105 & $(-0.81)$ & -0.113 & $(-0.88)$ \\
\hline Family difficulties - death of father & - & - & 0.169 & $(0.72)$ & 0.139 & $(0.60)$ & 0.143 & $(0.62)$ \\
\hline Family difficulties - death of mother & - & - & -0.333 & $(-1.14)$ & -0.285 & $(-0.98)$ & -0.380 & $(-1.32)$ \\
\hline Family difficulties - domestic tension & - & - & -0.133 & $(-1.19)$ & -0.124 & $(-1.13)$ & -0.086 & $(-0.78)$ \\
\hline Family difficulties - unemployment & - & - & -0.244 & $(-1.66)$ & -0.243 & $(-1.66)$ & -0.241 & $(-1.66)$ \\
\hline Family difficulties - alcoholism & - & - & -0.333 & $(-1.42)$ & -0.402 & $(-1.71)$ & -0.435 & $(-1.87)$ \\
\hline Father semi-professional worker & - & - & -0.035 & $(-0.36)$ & -0.035 & $(-0.32)$ & 0.002 & $(0.02)$ \\
\hline Father non-manual skilled worker & - & - & -0.047 & $(-0.45)$ & -0.090 & $(-0.76)$ & -0.056 & $(-0.46)$ \\
\hline Father manual skilled worker & - & - & -0.055 & $(-0.56)$ & -0.020 & $(-0.18)$ & 0.007 & $(0.06)$ \\
\hline Father semi-skilled worker & - & - & -0.084 & $(-0.81)$ & -0.028 & $(-0.24)$ & -0.037 & $(-0.31)$ \\
\hline Father unskilled worker & - & - & -0.010 & $(-0.08)$ & 0.030 & $(0.22)$ & 0.051 & $(0.37)$ \\
\hline \multicolumn{9}{|l|}{ Information at age 11} \\
\hline Number of siblings & - & - & - & - & -0.017 & $(-0.83)$ & -0.011 & $(-0.50)$ \\
\hline Height (meters) & - & - & - & - & 0.632 & $(1.80)$ & 0.517 & $(1.22)$ \\
\hline Weight (kilograms) & - & - & - & - & -0.011 & $(-3.33)$ & -0.009 & $(-2.13)$ \\
\hline Any physical handicap / disabling condition & - & - & - & - & -0.093 & $(-1.37)$ & -0.074 & $(-1.10)$ \\
\hline Behavioural-emotional problems index & - & - & - & - & -0.773 & $(-5.26)$ & -0.401 & $(-2.64)$ \\
\hline British Social Adjustment Guide total score & - & - & - & - & -0.966 & $(-6.02)$ & -0.681 & $(-4.19)$ \\
\hline Teacher assessment of cognitive ability & - & - & - & - & -0.060 & $(-0.36)$ & -0.057 & $(-0.34)$ \\
\hline Teacher assesses child as outstanding & - & - & - & - & 0.010 & $(0.25)$ & -0.003 & $(-0.07)$ \\
\hline General ability test score & - & - & - & - & 0.158 & $(1.00)$ & 0.194 & $(1.23)$ \\
\hline Reading comprehension test score & - & - & - & - & -0.648 & $(-3.94)$ & -0.433 & $(-2.45)$ \\
\hline Mathematics test score & - & - & - & - & 0.255 & $(2.01)$ & 0.136 & $(1.02)$ \\
\hline Copying designs test score & - & - & - & - & 0.203 & $(1.30)$ & 0.149 & $(0.96)$ \\
\hline Biological father not in household & - & - & - & - & -0.255 & $(-2.19)$ & -0.260 & $(-2.06)$ \\
\hline Father semi-professional worker & - & - & - & - & 0.016 & $(0.15)$ & 0.050 & $(0.47)$ \\
\hline Father non-manual skilled worker & - & - & - & - & 0.104 & $(0.90)$ & 0.137 & $(1.14)$ \\
\hline Father manual skilled worker & - & - & - & - & -0.046 & $(-0.43)$ & -0.017 & $(-0.15)$ \\
\hline Father semi-skilled worker & - & - & - & - & -0.072 & $(-0.64)$ & -0.027 & $(-0.23)$ \\
\hline Father unskilled worker & - & - & - & - & -0.005 & $(-0.04)$ & 0.013 & $(0.09)$ \\
\hline
\end{tabular}


TABLE 2: (Continued)

\begin{tabular}{|c|c|c|c|c|c|c|c|c|}
\hline \multicolumn{9}{|l|}{ Information at age 16} \\
\hline Number of siblings & - & - & - & - & - & - & -0.006 & $(-0.34)$ \\
\hline Height (meters) & - & - & - & - & - & - & 0.397 & $(1.07)$ \\
\hline Weight (kilograms) & - & - & - & - & - & - & -0.005 & $(-1.82)$ \\
\hline Behavioural-emotional problems index - parent & - & - & - & - & - & - & -1.302 & $(-7.32)$ \\
\hline Behavioural-emotional problems index - teacher & - & - & - & - & - & - & -0.695 & $(-3.58)$ \\
\hline Teacher assessment of cognitive ability & - & - & - & - & - & - & 0.119 & $(0.99)$ \\
\hline Reading comprehension test score & - & - & - & - & - & - & -0.450 & $(-2.87)$ \\
\hline Mathematics test score & - & - & - & - & - & - & 0.031 & $(0.24)$ \\
\hline Personality - cautious to impulsive & - & - & - & - & - & - & 0.035 & $(0.40)$ \\
\hline Personality - moody to even-tempered & - & - & - & - & - & - & 0.099 & $(1.40)$ \\
\hline Personality - timid to aggressive & - & - & - & - & - & - & 0.444 & (4.30) \\
\hline Personality - flexible to rigid & - & - & - & - & - & - & 0.017 & $(0.18)$ \\
\hline Personality - sociable to withdrawn & - & - & - & - & - & - & -0.304 & $(-4.05)$ \\
\hline Personality - lazy to hardworking & - & - & - & - & - & - & 0.129 & $(1.81)$ \\
\hline Trouble with the police & - & - & - & - & - & - & -0.140 & $(-2.05)$ \\
\hline Biological father not in household & - & - & - & - & - & - & 0.031 & $(0.34)$ \\
\hline Father semi-professional worker & - & - & - & - & - & - & -0.116 & $(-1.03)$ \\
\hline Father non-manual skilled worker & - & - & - & - & - & - & -0.105 & $(-0.84)$ \\
\hline Father manual skilled worker & - & - & - & - & - & - & -0.080 & $(-0.70)$ \\
\hline Father semi-skilled worker & - & - & - & - & - & - & -0.038 & $(-0.31)$ \\
\hline Father unskilled worker & - & - & - & - & - & - & -0.010 & $(-0.07)$ \\
\hline Log household weekly income & - & - & - & - & - & - & -0.005 & $(-0.18)$ \\
\hline Sample size & 7977 & & 7977 & & 7977 & & 7977 & \\
\hline R-squared & 0.012 & & 0.028 & & 0.043 & & 0.068 & \\
\hline Adjusted R-squared & 0.009 & & 0.020 & & 0.033 & & 0.054 & \\
\hline
\end{tabular}


TABLE 3: Observed Life Satisfaction versus Predictions from OLS and Ordered Probit Models

\begin{tabular}{|c|c|c|c|c|c|c|c|}
\hline & \multicolumn{6}{|c|}{ Observed Average Life Satisfaction } & \multirow[b]{2}{*}{ Total } \\
\hline & $\leq 5$ & 6 & 7 & 8 & 9 & 10 & \\
\hline$\leq 5$ & $\begin{array}{r}0 \\
{[50]}\end{array}$ & $\begin{array}{r}0 \\
{[13]}\end{array}$ & $\begin{array}{r}0 \\
{[20]}\end{array}$ & $\begin{array}{r}0 \\
{[17]}\end{array}$ & $\begin{array}{r}0 \\
{[5]}\end{array}$ & $\begin{array}{r}0 \\
{[5]}\end{array}$ & $\begin{array}{r}0 \\
{[110]}\end{array}$ \\
\hline \multirow[t]{2}{*}{6} & 23 & 3 & 5 & 4 & 1 & 3 & 39 \\
\hline & [0] & [0] & [0] & [0] & [0] & [0] & [0] \\
\hline \multirow[t]{2}{*}{7} & 240 & 167 & 272 & 332 & 167 & 73 & 1,251 \\
\hline & {$[0]$} & [0] & {$[0]$} & [0] & [0] & [0] & {$[0]$} \\
\hline \multirow[t]{2}{*}{8} & 450 & 559 & 1,239 & 2,279 & 1,478 & 518 & 6,523 \\
\hline & [665] & [718] & {$[1,522]$} & {$[2,643]$} & {$[1,691]$} & [604] & {$[7,843]$} \\
\hline \multirow[t]{2}{*}{9} & 2 & 4 & 28 & 52 & 57 & 21 & 164 \\
\hline & [0] & [L] & [2] & [/] & [1] & [b] & [24] \\
\hline \multirow[t]{2}{*}{10} & 0 & 0 & 0 & 0 & 0 & 0 & 0 \\
\hline & [0] & [0] & [0] & [0] & [0] & [0] & [0] \\
\hline Total & 715 & 733 & 1,544 & 2,667 & 1,703 & 615 & 7,977 \\
\hline
\end{tabular}

Note: Model specification 4 used. Figures in brackets are predictions from ordered probit model. 
TABLE 4: Childhood and Adult Predictors of Life Satisfaction at Age 50

\begin{tabular}{|c|c|c|c|c|c|}
\hline & (1) & $(2)$ & (3) & (4) & (5) \\
\hline $\begin{array}{l}\text { Childhood information included } \\
\text { Joint significance } p \text {-value }\end{array}$ & $\begin{array}{c}\text { YES } \\
0.000\end{array}$ & $\begin{array}{c}\text { YES } \\
0.000\end{array}$ & $\begin{array}{c}\text { YES } \\
0.045\end{array}$ & $\begin{array}{c}\text { YES } \\
0.119\end{array}$ & $\begin{array}{c}\text { YES } \\
0.096\end{array}$ \\
\hline \multicolumn{6}{|l|}{ Information at age 50} \\
\hline Log wages & $\begin{array}{l}- \\
-\end{array}$ & $\begin{array}{l}0.265 \\
(4.36)\end{array}$ & $\begin{array}{l}0.172 \\
(3.10)\end{array}$ & $\begin{array}{l}0.138 \\
(2.56)\end{array}$ & $\begin{array}{l}0.136 \\
(2.55)\end{array}$ \\
\hline Employed & - & $\begin{array}{l}0.546 \\
(6.24)\end{array}$ & $\begin{array}{l}0.417 \\
(5.22)\end{array}$ & $\begin{array}{l}0.421 \\
(5.43)\end{array}$ & $\begin{array}{l}0.439 \\
(5.73)\end{array}$ \\
\hline Unemployed & $\begin{array}{l}- \\
-\end{array}$ & $\begin{array}{l}-0.142 \\
(-0.86)\end{array}$ & $\begin{array}{l}-0.087 \\
(-0.57)\end{array}$ & $\begin{array}{l}0.012 \\
(0.08)\end{array}$ & $\begin{array}{l}0.074 \\
(0.51)\end{array}$ \\
\hline Married & $\begin{array}{l}- \\
-\end{array}$ & $\begin{array}{c}0.777 \\
(16.12)\end{array}$ & $\begin{array}{r}0.430 \\
(9.54)\end{array}$ & $\begin{array}{r}0.332 \\
(7.54)\end{array}$ & $\begin{array}{l}0.299 \\
(6.84)\end{array}$ \\
\hline Poor health & $\begin{array}{l}- \\
-\end{array}$ & $\begin{array}{c}-1.080 \\
(-17.29)\end{array}$ & $\begin{array}{c}-0.740 \\
(-12.80)\end{array}$ & $\begin{array}{c}-0.688 \\
(-12.27)\end{array}$ & $\begin{array}{c}-0.661 \\
(-11.89)\end{array}$ \\
\hline Degree & - & $\begin{array}{l}0.147 \\
(1.86) \\
\end{array}$ & $\begin{array}{l}0.122 \\
(1.70) \\
\end{array}$ & $\begin{array}{l}0.097 \\
(1.39) \\
\end{array}$ & $\begin{array}{l}0.089 \\
(1.30) \\
\end{array}$ \\
\hline Lagged life satisfaction & & - & & & \\
\hline Satisfaction at age 46 & - & $\begin{array}{l}- \\
-\end{array}$ & $\begin{array}{c}0.546 \\
(34.59)\end{array}$ & $\begin{array}{c}0.435 \\
(26.65)\end{array}$ & $\begin{array}{c}0.400 \\
(24.35)\end{array}$ \\
\hline Satisfaction at age 42 & - & $\begin{array}{l}- \\
-\end{array}$ & $\begin{array}{l}- \\
-\end{array}$ & $\begin{array}{c}0.238 \\
(19.55)\end{array}$ & $\begin{array}{c}0.202 \\
(\mathbf{1 6 . 2 2})\end{array}$ \\
\hline Satisfaction at age 33 & - & - & - & - & $\begin{array}{c}0.157 \\
(11.16)\end{array}$ \\
\hline $\begin{array}{l}\text { Sample size } \\
\text { R-squared } \\
\text { Adjusted R-squared }\end{array}$ & $\begin{array}{l}6005 \\
0.054 \\
0.035 \\
\end{array}$ & $\begin{array}{l}6005 \\
0.174 \\
0.156 \\
\end{array}$ & $\begin{array}{l}6005 \\
0.313 \\
0.299 \\
\end{array}$ & $\begin{array}{l}6005 \\
0.355 \\
0.341 \\
\end{array}$ & $\begin{array}{l}6005 \\
0.369 \\
0.355 \\
\end{array}$ \\
\hline
\end{tabular}

Notes: OLS regressions. Dependent variable is life satisfaction at age 50. $t$-statistics in parentheses. Bold denotes statistical significance at the $5 \%$ level according to Benjamini and Hochberg (1995) adjusted $p$ values. - indicates that variable is not included in the model. 


\section{Appendix - Variable Definitions}

Parent assessed behavioural-emotional problems index at age 7 and age 11

Parents are asked whether a list of behaviours never happen (1), sometimes happen (2), or frequently happen (3) at the current time. The listed behaviours are: (a) Has difficulty in settling to anything for more than a few moments; (b) Prefers to do things on his/her own rather than with others; (c) Is bullied by other children; (d) Destroys own or others belongings; (e) Is miserable or tearful; (f) Is squirmy or fidgety; (g) Worries about many things; (h) Is irritable, quick to fly off the handle; (i) Sucks thumb or finger during day; (j) Is upset by new situation, by things happening for first time; (k) Has twitches or mannerisms of the face, eyes or body; (l) Fights with other children; (m) Bites nails; and (n) Is disobedient at home. The index is constructed by averaging the responses, and then standardising such that 0 equals the minimum observed value and 1 equals the maximum observed value.

Parent assessed behavioural-emotional problems index at age 16

Parents are asked whether a list of behaviours doesn't apply (1), applies somewhat (2), or certainly applies (3) to the cohort member. The listed behaviours are: (a) Very restless, has difficulty staying seated for long; (b) Squirmy, fidgety child; (c) Often destroys own or others' property; (d) Frequently fights or is extremely quarrelsome with other children; (e) Not much liked by other children; (f) Often worried, worries about many things; (g) Tends to do things on own - rather solitary; (h) Irritable, is quick to 'fly of the handle'; (i) Often appears miserable, unhappy, tearful or distressed; (j) Has twitches, mannerisms or tics of the face or body; (k) Frequently sucks thumb or fingers; (l) Frequently bites nails or fingers; (m) Is often disobedient; (n) Cannot settle to anything for more than a few moments; (o) Tends to be fearful or afraid of new things or new situations; (p) Fussy or over-particular; (q) Often tells lies; and (r) Bullies other children. The index is constructed by averaging the responses, and then standardising such that 0 equals the minimum observed value and 1 equals the maximum observed value.

Teacher assessed behavioural-emotional problems index at age 16

Teachers are asked whether a list of behaviours doesn't apply (1), applies somewhat (2), or certainly applies (3) to the cohort member. The listed behaviours include the behaviours in the parent assessed index at age 16, and also includes: (s) Truants from school; (t) Tends to be absent from school for trivial reasons; (u) Has stolen things on one or more occasions in the past 12 months; (v) Unresponsive, inert or apathetic; (w) Often complains of aches or pains; (x) Has had tears on arrival at school or has refused to come into the building in the past 12 months; (y) Has a stutter or stammer; and (z) Resentful or aggressive when corrected. The index is constructed by averaging the responses, and then standardising such that 0 equals the minimum observed value and 1 equals the maximum observed value.

British Social Adjustment Guide total score at age7 and age 11

Teachers are asked to underline phrases that best describe the child's behaviour from a long list of phrases that are grouped within syndromes. The total score is constructed by adding together the syndrome totals to give a total amount of behavioural deviance or maladjustment. The syndromes used in the total score are: Unforthcomingness, Withdrawal, Depression, Anxiety for acceptance by adults, Hostility towards adults, 'Writing off' of adults and adult standards, Anxiety for acceptance by children, Hostility towards children, Restlessness, 'Inconsequential' behaviour, Miscellaneous symptoms, Miscellaneous nervous symptoms. The total score is standardised such that 0 equals the minimum observed value and 1 equals the maximum observed value.

Teacher assessed personality at age 16

Teachers are asked to rate whether the child is: cautious or impulsive; moody or even-tempered; timid or aggressive; flexible or rigid; sociable or withdrawn; lazy or hardworking. For each personality they can respond from 1 (left-hand personality clearly applies) to 5 (right-hand personality clearly applies). A score of 3 signifies that the child is midway between the two personalities. The score for each personality 
pairing is standardised such that 0 means the left-hand personality clearly applies and 1 means the righthand personality clearly applies.

Teacher assessment of cognitive ability at age 7

Teachers are asked to rate the cohort member in relation to all children of this age with regard to: (i) oral ability; (ii) awareness of the world around him general knowledge; (iii) reading; (iv) creativity; and (v) number work. For each aspect of ability the teacher gives a score from 1 to 5 . The index is constructed by averaging the responses, and then standardising such that 0 equals the minimum observed value and 1 equals the maximum observed value.

Teacher assessment of cognitive ability at age 11

Teachers are asked to rate the cohort member in relation to all children of this age with regard to: (i) general knowledge; (ii) number work (iii) use of books; and (iv) oral ability. For each aspect of ability the teacher gives a score from 1 to 5 . The index is constructed by averaging the responses, and then standardising such that 0 equals the minimum observed value and 1 equals the maximum observed value.

Teacher assessment of cognitive ability at age 16

Teachers are asked to rate the cohort member with regard to: (i) mathematics; (ii) English (iii) modern languages; (iv) science; (v) practical subjects; and (vi) social studies. For each aspect of ability the teacher gives a score from 1 to 5 . The index is constructed by averaging the responses, and then standardising such that 0 equals the minimum observed value and 1 equals the maximum observed value. 